\title{
TECHNOLOGICAL LEADERSHIP AND PERSISTENCE OF MONOPOLY UNDER ENDOGENOUS ENTRY: STATIC VERSUS DYNAMIC ANALYSIS
}

\author{
Eugen Kováč \\ Viatcheslav Vinogradov \\ Krešimir Žigić
}
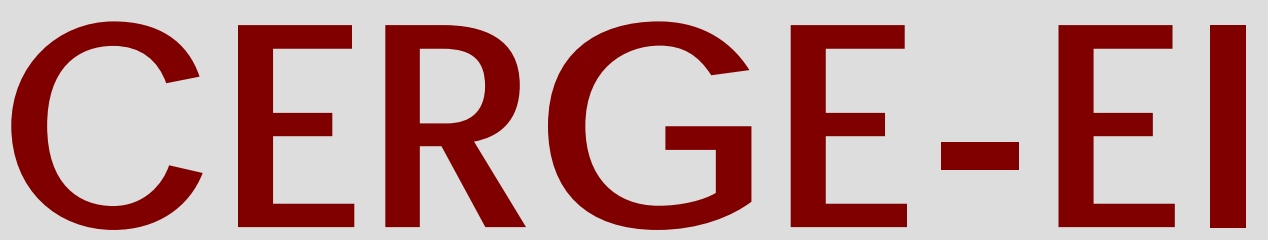

Charles University Centerfor Ec onomic Research and Graduate Education Academy of Sciences of the Czech Republic Ec onomic s Institute 


\title{
Working Paper Series (ISSN 1211-3298)
}

\section{Technological Leadership and Persistence of Monopoly under Endogenous Entry: Static versus Dynamic Analysis}

\author{
Eugen Kováč \\ Viatcheslav Vinogradov \\ Krešimir Žigić
}

CERGE-EI

Prague, December 2009
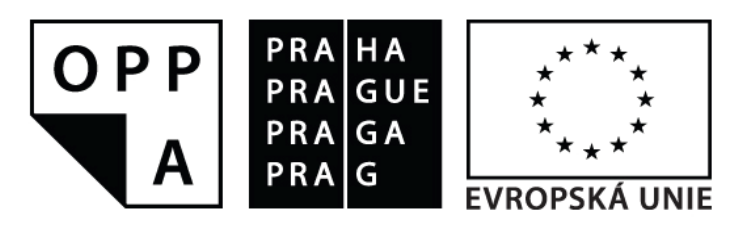

EVROPSKÝ SOCIÁLNÍ FOND

PRAHA \& EU: INVESTUJEME DO VAŠÍ BUDOUCNOSTI

Projekt je financován Evropským sociálním fondem, rozpočtem hl. města Prahy a státním rozpočtem 
ISBN 978-80-7343-203-4 (Univerzita Karlova. Centrum pro ekonomický výzkum a doktorské studium)

ISBN 978-80-7344-192-0 (Národohospodářský ústav AV ČR, v.v.i.) 


\title{
Technological Leadership and Persistence of Monopoly under Endogenous Entry: Static versus Dynamic Analysis*
}

\author{
Eugen Kováč ${ }^{\mathrm{a}, \mathrm{b}} \quad$ ViatcheslaV VinOGRadov ${ }^{\mathrm{b}, \mathrm{c}}$ \\ KREŠIMIR ŽIIGIĆ ${ }^{b, d}$
}

December 2009

\begin{abstract}
We build a dynamic oligopoly model with endogenous entry in which a particular firm (leader) invests in an innovation process, facing the subsequent entry of other firms (followers). We identify conditions that make it optimal for the leader in the initial oligopoly situation to undertake pre-emptive R\&D investment (strategic predation) eventually resulting in the elimination of all followers. Compared to a static model, the dynamic one provides new insights into the leader's intertemporal investment choice, its optimal decision making, and the dynamics of the market structure over time. We also contrast the leader's investment decisions with those of the social planner.
\end{abstract}

\begin{abstract}
Abstrakt
Tvoříme dynamický oligopolní model s endogenním vstupem, ve kterém konkrétní firma (vůdce) investuje v inovačním procesu a čelí opětovným pokusům o vstup z raad rivalů (následovníci). Nalézáme podmínky, při kterých je pro vůdce optimální podniknout v situaci, kdy na počátku existuje oligopol, preventivní R\&D investice (strategické predátorování), které případně vyústí v úplnou eliminaci všech konkurentů. V porovnání se statickým modelem se ukazuje, že dynamický model poskytuje nový pohled na volby vůdce trhu napříc obdobími, jeho rozhodnutí a dynamiku struktury trhu v čase. Rovnež porovnáváme investiční rozhodnutí vůdce s rozhodnutími plánovače.
\end{abstract}

Keywords: dynamic oligopoly, endogenous entry, persistence of monopoly, strategic predation, accommodation

JEL Classification: L12, L13, L41

*The authors are grateful to J. Engwerda, P. Katuščák, C. Kiedaisch, S. Slobodyan, J. Vandekerckhove, and three anonymous referees for helpful comments and suggestions, L. Straková and R. Stock for English editing assistance, and Z. Budinová and V. Strohush for research assistance on earlier drafts of the paper. In addition, we have benefited from comments received at the seminar at the University of Zurich and conferences CEF 2006 in Limassol, EEA-ESEM 2006 in Vienna, Intertic conference 2007 in Milan, and EARIE 2009 in Ljubljana. The standard caveat applies.

${ }^{a}$ Department of Economics, University of Bonn, Germany; e-mail: eugen.kovac@uni-bonn.de; URL: www. uni-bonn.de/ ${ }^{\text {kovac. }}$

${ }^{\mathrm{b}}$ CERGE-EI, a joint workplace of the Center for Economic Research and Graduate Education at Charles University in Prague and the Economics Institute of the Czech Academy of Sciences.

${ }^{\mathrm{c}}$ Corresponding author; address: CERGE-EI, P.O.Box 882, Politických vězñu 7, 11121 Prague 1, Czech Republic; e-mail: viatcheslav.vinogradov@cerge-ei.cz.

${ }^{\mathrm{d}}$ E-mail: kresimir.zigic@cerge-ei.cz. 


\section{Introduction}

Is monopoly an environment conducive to innovation? Is there persistence of monopoly, or is there a change in the identity of the innovating firm ("leapfrogging")? These questions are not new among economists, but recently they seem to have been rekindled. In an issue of The Economist (2004), the authors of the already-celebrated column "Economics Focus" in their provocatively-entitled article "Slackers or Pace-Setters: Monopolies may have more incentives to innovate than economists have thought" claimed that monopolies may have a far more prominent role in generating innovation than previously thought. The authors further expressed doubts about the prevailing economic theory according to which "a monopolist should have far less incentives to invest in creating innovations than a firm in a competitive environment." Apparently, there is some controversy regarding the role of market power and monopolies in creating innovations, and the key a resolution it lies in the underlying incentives to engage in innovation.

Recent empirical evidence seems to support these Schumpeterian allegations from The Economist: There is a positive relationship between market power and the intensity of innovation (see, for instance, Blundell et al., 1999; Carlin et al., 2004; Aghion and Griffith, 2004). Commenting on this empirical evidence, Etro (2004) stated that it "is consistent with pre-emptive R\&D investment by the leaders" (p. 282). In other words, there will be only one firm at the end of the day, but this firm would display far more competitive behavior than the standard monopolist; it would generate a higher flow of $\mathrm{R} \& \mathrm{D}$, charge a lower price, and produce more. As a consequence of such strategic behavior, the Chandlerian phenomenon of the persistence of monopoly can arise. ${ }^{1}$

There are many real-world examples of monopolistic or dominant firms that are technological leaders and that invest more in innovation and R\&D than their rivals (see Etro, 2004), and that survive over a long period of time. AT\&T, a giant American telecommunications company, is a good case in point. Founded in 1885, the company is one of the largest telephone companies and cable television operators in the world. AT\&T provides voice, video, data, and Internet telecommunications services to businesses, consumers, and government agencies. After becoming the first long-distance telephone network in the US, AT\&T made huge investments in research and development. As a result, the company obtained near-monopoly power on long-distance phone services. Heavy investments in R\&D together with aggressive behavior on the market allowed AT\&T to acquire crucial inventions and to spread its near monopoly power to other markets. The company both bought patents for significant innovations and undertook innovations itself. ${ }^{2}$

\footnotetext{
${ }^{1}$ See Sutton (2007) for the theoretical and empirical issues concerning the measurement of the persistence of market leaders.

${ }^{2}$ For instance, during the early 1920s, AT\&T bought Lee De Forest's patents on the "audion", the first triode vacuum tube, which let it enter the radio business. On the other hand, the first commercial communications satellite, Telstar I, was commissioned by AT\&T in 1962.
} 
The above observations on the relations among innovation, technological leadership, and market power motivate our paper in that we aim to describe and analyze a particular setup in which a persistence of monopoly can arise in the long run. More specifically, we study the situation in which the technological leader facing endogenous entry may undertake pre-emptive $\mathrm{R} \& \mathrm{D}$ investment (or, in our words, may adopt strategic predation), that eventually leads to the exit of the follower firms and/or prevents or limits the entry of new firms. We contrast this situation with one in which the leader (within the same setup) accommodates the endogenous entry of followers, that is, co-exists with the followers in an oligopolistic market structure. This comparison will enable us to study both positive aspects of the two main strategies of accommodation and strategic predation (for instance, which strategy yields higher R\&D intensity), and normative aspects (social welfare implications) of the two resulting market structures: oligopoly versus (constrained or unconstrained) monopoly and their respective performances vis-à-vis a social planner. The latter aspect, as we will see, carries important policy implications.

Our paper is related to a recent stream of industrial economics literature on endogenous entry (see, for instance, Etro, 2004, 2006 and 2007; Erkal and Piccinin, 2007; Davidson and Mukerjee, 2008; and Creane and Konishi, 2009). For instance, both Etro (2006, 2007) and Creane and Konishi (2009) examine, among other things, both positive and social welfare effects of strategic predation that a technological leader may exhibit when faced with endogenous entry and exit. In modelling those features they rely on a three- or two-stage version of the static Cournot oligopoly. The novel feature of our approach, however, is that we utilize an explicit dynamic model in tackling these issues and contrast it with its static (or quasi-dynamic) counterpart. This comparison can be considered as the topic per se of our paper. Since strategic innovations and entry are inherently dynamic phenomena, we argue that a suitable model aimed at capturing both accommodating and pre-emptive, or predatory, behavior of the dominant firm should be explicitly dynamic. Furthermore, to emphasize the role of the technological leader we assume that the leading firm is the only one that invests in innovation.

The concept of two-stage competition used to be a typical tool to tackle standard strategic interactions like the case when the incumbent firm undertakes a strategic investment in the first stage and then there is competition in quantities or prices in the last, second stage. This concept concentrates on identifying "strategic effects" that influence first-period behavior and aims to characterize the resulting strategic rivalry. It has proven successful in that the same strategic principles (e.g., overinvestment or underinvestment) apply in many economic environments, and the comparative static results from static oligopoly theory can be used to provide information about strategic behavior (see Fudenberg and Tirole, 1984; Tirole, 1990; Shapiro, 1989; and Etro, 2004 and 2006). ${ }^{3}$

\footnotetext{
${ }^{3}$ Etro (2006) however demonstrated that allowing for endogenous entry dramatically simplifies the
} 
Adding endogenous entry in the above two-stage framework, however, would require an in-between (second) stage of the game that allows the competitors to decide whether to enter the market or not after they observe the strategic move ( $R \& D$ investment) on the side of incumbent (leader) firm in the first stage. Thus, our static benchmark game will be, in fact, a three-stage Cournot game in which one firm ("leader") has a strategic advantage in the form of a prior (first-stage) investment in $R \& D$ that leads to a unit cost decrease. In the last (third) stage the leader and followers compete in quantities.

The concept of a two-stage (or multi-stage) oligopoly game relies, however, on an artificial time structure and neglects potential intertemporal tradeoffs. From the perspective of a full-fledged dynamic model, it gives at best the steady state values of the true underlying dynamic game. Thus, it neglects the dynamic adjustment process and lacks the explicit motion of the strategic variables over time and their accompanying comparative dynamics. More importantly, the set of strategies available to firms may be richer than in the corresponding static model. In particular, the leader may go for early or late predation, and the attractiveness of the predation strategy crucially depends on the leader's ability to translate its investment into an advantage on the product market.

To concentrate on the strategic aspects within the dynamic model we push the output decision to the background and deal with the so-called reduced-form profit function, making the firms' flows of profits a function of unit costs. The unit costs of the firms and the number of entrants serve as so-called state variables that are governed through the control variable, namely $R \& D$ expenditures. Another important feature here is that passage from a three-stage model to a dynamic one requires the introduction of a specific adjustment parameter that captures the speed with which the R\&D investments translate into the unit cost reduction (see, for example, Fersthman and Kamien, 1987; and Stenbacka and Tombak, 1997 for a utilization of a similar approach). This makes our model more realistic because now it mimics the unavoidable time delay between $R \& D$ investment and the corresponding $\mathrm{R} \& \mathrm{D}$ output. The dynamic approach also enables us to study the behavior of the strategic variable over time and some of its comparative dynamic effects, as well as the adjustment process, all of which are missing in the simple three-stage framework.

Finally and most importantly, in an explicit dynamic model we can analyze how the optimal strategy of a firm that possesses a strategic advantage may lead to a change in market structure over time and thus create a persistence of monopoly. This phenomenon cannot be modelled within a static three-stage game. In other words, the strategic advantage of the leader may enable it to exhibit pre-emptive behavior (or strategic predation) on its rivals, eventually turning the initially oligopolistic market structure into a monopoly. In that case, the persistence of monopoly occurs endogenously due to contin-

taxonomy of business strategies since all that matters is whether strategic investment hurts the incumbent. 
uous investments that do not disappear once the monopoly position has been achieved. The underlying dynamic optimization problem then involves an additional component compared to the case when the leader chooses the accommodation strategy. Namely, via its $R \& D$ investments the leader also determines how quickly predation takes place, i.e., at which point in time all rivals are eliminated.

\section{Overview of main results}

Our analysis provides the following new insights:

(a) The technological leader adopts the accommodation strategy only when its R\&D efficiency is "low" or/and the size of the market is relatively large (more precisely, when fixed costs are small relative to the size of the market). In all other cases, the leader opts for strategic predation aiming to achieve the monopoly position after a certain time $T$.

(b) During the predation period (up to a certain time $T$ ), the leader might even be willing to incur losses in order to enjoy a monopoly profit from time $T$ onward. Thus, unlike in the static game, in a fully dynamic model the costs of predation last for a certain period of time and have to be contrasted to the infinite stream of monopoly profit earned afterwards. As these costs depend on the speed of the adoption of new technology, strategic predation becomes a more attractive strategy to pursue when the adoption of new technology accelerates. In the limit case, when the adoption is instantaneous, the dynamic model essentially reduces to the static one.

(c) The time pattern of $R \& D$ investments crucially depends on the equilibrium strategy: If accommodation is the optimal strategy, then the leader chooses an R\&D path which steadily increases over time towards a unique steady-state value. If, on the other hand, the strategic predation strategy becomes optimal, then the leader first invests significantly in R\&D in order to achieve the monopoly position at time $T$. The shorter the target time $T$, by which all other follower firms are forced to exit, the higher the "predatory" R\&D investment has to be. In other words, the level of optimal R\&D investment decreases with an increase in target time. (Note that it is not viable by assumption to force an immediate exit of all other firms, since it would then require an infinite amount of $R \& D$, when the speed of adjustment is finite.)

(d) Once all rivals are eliminated, the leader may continue to further increase its R\&D investment and become a so-called unconstrained monopolist. Alternatively, the leader may behave as a constrained monopolist that keeps its investment at a low 
level just high enough to prevent rivals from re-entering the market. Nevertheless, such an investment level is still higher than the one observed in the case of accommodation.

(e) Regarding social welfare considerations, we show that the social planner choosing the flow of R\&D investment to maximize the sum of profit and consumer surplus while keeping the market structure unchanged also prefers strategic predation to accommodation when its R\&D efficiency is "large" and/or the size of the setup costs relative to the size of the market is large. Moreover, the social planner would prefer a longer predation time than the profit-maximizing leader if the combination of R\&D efficiency and the relative size of fixed costs is below a certain threshold curve. On the other hand, the social planner can be more aggressive than the leader in the sense that the planner prefers a shorter predation time if another threshold curve is surpassed (this threshold corresponds to the situation when both R\&D efficiency and the relative size of fixed costs are large).

The remainder of the paper proceeds as follows. The static model is analyzed in Section 2. Section 3 introduces the dynamic model. In the subsequent sect ions we study the leader's strategies of accommodation (Section 4) and strategic predation (Section 5). Section 6 provides a comparison of these strategies and determines the leader's optimal behavior in the long run. Section 7 presents the welfare analysis, where we contrast the leader's investment decision with that of the social planner. Section 8 concludes and discusses the potential policy implications of our results.

\section{$2 \quad$ Static Model}

\subsection{Equilibrium with Endogenous Entry}

In this section we describe the market game with endogenous entry that has been recently brought into attention by Etro $(2004,2006,2007)$. We consider a market for a single homogeneous good. The good is produced by one leader firm (indexed by 0 ) and potentially also by several identical follower firms (indexed by $i=1,2, \ldots$ ). Following Etro (2007), we assume that firms compete in quantities with endogenous entry. The game involves two stages so far. In the first stage all firms simultaneously decide whether to be active in the market or not. By being active, a firm incurs fixed setup costs $F$ that are sunk later; not being active does not involve any costs. In the second stage, all active firms compete in quantities à la Cournot (see Etro, 2007 for details). The equilibrium of such a game is sometimes called Marshall equilibrium (see Etro, 2007) and is characterized by the number of followers that become active, their optimal outputs and the optimal output of the leader. The equilibrium number of active followers is the maximal one yet 
delivering non-negative profits in the subsequent Cournot competition. If even only one follower is not able to earn a positive profit, the leader is the only firm active and becomes a monopolist (we assume that the leader is able to earn a non-negative profit).

Production in the second stage involves unit variable costs: all followers produce the good at constant unit (variable) costs $\bar{c}$, whereas the leader produces the good at constant unit (variable) $\operatorname{costs} c_{0}$, where $c_{0} \leq \bar{c}$. The leader's unit costs may be lower than $\bar{c}$ due to previous R\&D investments. ${ }^{4}$ Note that the leadership in our setup implies the existence of an incumbent firm rather than the firm having a standard first-mover advantage. That incumbent firm is the only one assumed to be capable of investing in innovation. Thus, in a sense, our leader firm acts as a technological rather than Stackelberg leader.

In the following sections we embed this model into a static model (Section 2.2) and a dynamic model (Section 3) that specifically describe the leader's R\&D investments decisions. Via R\&D investment, the leader firm can affect its unit costs and thus indirectly - the number of followers. Therefore, we first extend the model to a threestage (static) setup by introducing an initial stage in which the leader decides on an $R \& D$ investment that lowers its unit costs. Later on we consider a dynamic model where the number of active followers as well as their outputs adjust instantaneously to the change in the leader's unit costs so that the market is in Marshall equilibrium at every point in time. The leader solves a dynamic optimization problem with its unit costs being a state variable following a certain law of motion and with investment being a control variable.

We consider a linear inverse demand function: $p=A-Q$, where $Q$ denotes the market demand and $A-\bar{c}$ captures the size of the market (where $A>\bar{c}$ ). If $n$ is the number of followers active in the second stage, then in the Cournot equilibrium the output of the leader $q_{0}$ and the output of each follower $q_{i}$ (for $i=1, \ldots, n$ ) appear to be

$$
q_{0}=\frac{A-\bar{c}+(n+1)\left(\bar{c}-c_{0}\right)}{n+2} \quad \text { and } \quad q_{i}=\frac{A-\bar{c}-\left(\bar{c}-c_{0}\right)}{n+2} .
$$

The leader's and the followers' (gross) profits are then $\Pi_{0}=q_{0}^{2}$ and $\Pi_{i}=q_{i}^{2}$, respectively.

In equilibrium, the number of active followers satisfies the zero-profit condition $\Pi_{i}=$ $F$, where $F$ are fixed costs incurred in the first stage and sunk later. Thus each follower's equilibrium output is equal to $q_{i}=\sqrt{F}$ and the equilibrium number of followers is

$$
n=\frac{A-2 \bar{c}+c_{0}}{\sqrt{F}}-2
$$

For simplicity and tractability purposes, we use a continuous variable to approximate the number of followers. More specifically, we assume that $n$ can take values from the interval $[1, \infty)$ or be equal to 0 , where the latter means that all followers are crowded out

\footnotetext{
${ }^{4}$ For simplicity, we refer to these costs as "unit costs", instead of the more appropriate term "unit variable costs".
} 
from the market and the leader is a monopolist. ${ }^{5}$

Taking the zero-profit condition into account, a direct computation then yields the following equilibrium quantities and price (in the case of entry):

$$
q_{0}=\bar{c}+\sqrt{F}-c_{0}, \quad q_{i}=\sqrt{F}, \quad p=\bar{c}+\sqrt{F} .
$$

In the case of no entry, the leader becomes a monopolist, setting the monopoly quantity $q_{M}=\frac{1}{2}\left(A-c_{0}\right)$ that results in the monopoly price $p_{M}=\frac{1}{2}\left(A+c_{0}\right)$ and generates the monopoly profit of $\Pi_{M}=q_{M}^{2}$.

Now, entry occurs when $n \geq 1$ in equilibrium. As follows from (1), the latter condition is equivalent to

$$
c_{0}>\hat{c}, \quad \text { where } \quad \hat{c}=-A+2 \bar{c}+3 \sqrt{F} .
$$

If the reverse inequality strictly holds, the leader becomes a monopolist. ${ }^{6}$ The value $\hat{c}=-A+2 \bar{c}+3 \sqrt{F}$ thus represents a critical value of the leader's unit costs that determines the resulting market structure. If the leader's costs are sufficiently high, i.e., the gap between the leader and the followers is sufficiently small, entry occurs with the number of entrants increasing in the leader's costs. On the other hand, if the leader's costs fall below this critical value, the leader becomes a monopolist.

Note also that in the symmetric case when $c_{0}=\bar{c}$ (without any prior investment), entry occurs if and only if $\Phi \leq \frac{1}{3}$, where

$$
\Phi=\frac{\sqrt{F}}{A-\bar{c}} .
$$

In other words, to allow entry, fixed costs need to be sufficiently small relative to the size of the market. Otherwise, entry never occurs in equilibrium. Thus, in what follows, we will restrict our analysis to the case $\Phi \leq \frac{1}{3}$.

\subsection{Leader's Investment Decision}

In this section we add an initial stage to the game and consider a game where the (Marshall) equilibrium with endogenous entry is preceded by an investment stage. We further assume that the leader has ex-ante identical unit (variable) costs with the followers. Thus,

\footnotetext{
${ }^{5}$ When $n$ is defined as in (1) and $n \geq 1$, then the "actual" number of active followers is equal to the (unique) integer that lies in the interval $(n-1, n]$.

${ }^{6}$ If $c_{0}=\hat{c}$, there is only one active follower who is actually indifferent between being active or not. At this point, both the leader's quantity and profit (as functions of $c_{0}$ ) have a jump downwards. More precisely, the limits of the leader's quantity (when $c_{0}$ approaches $\hat{c}$ ) from the left and from the right are $\hat{q}_{0}=A-\bar{c}-2 \sqrt{F}$ and $\hat{q}_{M}=A-\bar{c}-\frac{3}{2} \sqrt{F}$, respectively. Thus, when $c_{0}$ is the outcome of a preceding $\mathrm{R} \& \mathrm{D}$ investment, in equilibrium the leader also becomes a monopolist for $c_{0}=\hat{c}$. In other words, the leader's equilibrium profit is continuous in $c_{0}$ from the right.
} 
without any investment, its unit costs are $c_{0}=\bar{c}$. In other words, initially all firms have access to the old technology, implying that the initial level of both fixed and unit costs are the same for all firms. We, however, assume that the R\&D investments of the leader do not affect its fixed costs but only its unit costs.

In order to describe the effects of $\mathrm{R} \& \mathrm{D}$ investments, we employ a simple $R \mathscr{E} D$ production function where the leader lowers its unit costs by $\sqrt{g x}$ if it invests an amount of $x$ (see Chin and Grossman, 1990, or Žigić, 1998 for the use of such a function). The variable $x$ represents the level of $\mathrm{R} \& \mathrm{D}$ expenditures that are incurred in the investment stage and sunk later. The parameter $g$ describes the efficiency of the R\&D process; we assume that $g \in(0,4)$ where the upper bound is determined by the positivity requirement imposed on the monopoly output and investments in the equilibrium. For convenience we introduce the transformation $x=z^{2}$ and in what follows use $x$ and $z$ interchangeably to refer to investment size or investment level. In this notation, after investing the amount of $z^{2}$, the leader's unit costs become

$$
c_{0}(z)=\bar{c}-\sqrt{g} z
$$

for $z \in[0, \bar{c} / \sqrt{g}]$.

The resulting market structure depends on the size of the leader's investments. Combining (3) and (4), we find that if the leader's investment level $z$ is below the threshold $\hat{z}$, i.e.,

$$
z<\hat{z}, \quad \text { where } \quad \hat{z}=\frac{\bar{c}-\hat{c}}{\sqrt{g}}=\frac{A-\bar{c}-3 \sqrt{F}}{\sqrt{g}},
$$

then $c_{0}>\hat{c}$ and entry occurs, where the equilibrium values are given by (1) and (2). In such a case, we say that the leader chooses an accommodation strategy. Alternatively, the leader may choose an investment level $z \geq \hat{z}$ (or, equivalently, $c_{0} \leq \hat{c}$ ) that leads to a monopoly. In such a case, we say that the leader chooses a strategic predation strategy.

The leader maximizes its net profit $q^{2}-z^{2}-F$, where $q=q_{0}$ for $c_{0}>\hat{c}, q=q_{M}$ for $c_{0} \leq \hat{c}$, and the relation between investments and unit costs is given by (4). In the case of accommodation, the optimal level of investment and the resulting equilibrium output of the leader are

$$
z_{A}^{*}=\frac{\sqrt{g}}{1-g} \sqrt{F} \quad \text { and } \quad q_{A}^{*}=\frac{1}{1-g} \sqrt{F},
$$

which allows for the entry of $n^{*}=\frac{1}{\Phi}-\frac{2-g}{1-g}$ followers. Entry occurs if and only if $z_{A}$ does not exceed $\hat{z}$ (or $n^{*} \geq 1$ ). We may rewrite this condition as $\Phi \leq \phi_{A}(g)$, where $\phi_{A}(g)=\frac{1-g}{3-2 g}$. Note that the necessary condition for accommodation is $g<1$. If $g \geq 1$, then the leader's accommodation profit is increasing in $z$ on $[0, \hat{z})$. In this case, accommodation is not 
optimal; the leader chooses $z \geq \hat{z}$ and becomes a monopolist.

Analogously, in the case of strategic predation, the optimal level of investment and the leader's output are

$$
z_{M}^{*}=\frac{\sqrt{g}}{4-g}(A-\bar{c}) \quad \text { and } \quad q_{M}^{*}=\frac{2}{4-g}(A-\bar{c}) .
$$

Reasoning as above, we conclude that the leader becomes a monopolist if and only if $z_{M}^{*}$ (weakly) exceeds $\hat{z}$, which is equivalent to $\Phi \geq \phi_{M}(g)$, where $\phi_{M}(g)=\frac{2(2-g)}{3(4-g)} \cdot{ }^{7}$ In such a case, the leader's profit is decreasing in $z$. Because the profit has a jump upwards in $z=\hat{z}$, the leader's profit may also be maximized at this point, leading to a monopoly with output $\hat{q}_{M}=A-\bar{c}-\frac{3}{2} \sqrt{F}$ (see footnote 6 ). In this case the leader actually chooses a minimal investment level that prevents the followers from entering (i.e., $z=\hat{z}$ ) and becomes in some sense a constrained monopolist.

A comparison of the resulting profit with the profit from accommodation reveals that accommodation is optimal if and only if

$$
\left(1-\frac{3-2 g}{1-g} \Phi\right) \sqrt{\frac{1-g}{g}}>\sqrt{\Phi\left(1-\frac{7}{4} \Phi\right)} .
$$

Note that inequality (5) holds for $\Phi=0$, whereas for $\Phi=\phi_{A}(g)$ its sign is reversed because the left-hand side of (5) vanishes. Direct computation yields that for any $g \in(0,1)$ there is a critical value of $\Phi$, namely $\phi_{0}(g)=2(1-g)(6-\sqrt{5 g}-3 g) /\left(36-41 g+9 g^{2}\right)$, such that the leader chooses accommodation if and only if $\Phi$ lies below this critical value.

Figure 1 shows the regions of parameters $g$ and $\Phi$, where accommodation (region A) and strategic predation (the union of regions $C M_{1}, C M_{2}$, and $U M$ ) are chosen by the leader. ${ }^{8}$ For $\Phi$ close to $\frac{1}{3}$, the leader chooses strategic predation with the optimal monopoly investment. When the entry costs decrease ( $\Phi$ surpasses the threshold $\left.\phi_{M}(g)\right)$, then the optimal monopoly investment leads to entry. In this case the leader becomes a constrained monopolist choosing the minimal investment level $z=\hat{z}$ that still prevents the followers from entering. For even lower fixed costs (when $\Phi \leq \phi_{0}(g)$ ), the leader chooses the accommodation strategy.

\footnotetext{
${ }^{7}$ Note also that the above results require $g<4$. If $g \geq 4$, the leader's profit is increasing in $z$ on $(\hat{z}, \infty)$ and converges to infinity when $z \rightarrow \infty$. Thus, in order to ensure the existence of the maximum, we assume $g<4$. Moreover, economic relevance requires that the unit costs remain positive, i.e., $c_{M}^{*}>0$ or equivalently $g<4 \bar{c} / A$ (where $4 \bar{c} / A<4$ ). As all our results will actually be formulated only in terms of the size of the market $A-\bar{c}$ and not in terms of $A$ and $\bar{c}$, we omit this condition from further elaborations. This is without loss of generality, as for any size of the market and any $g \in(0,4)$, we can find values of $A, \bar{c}$ that yield such a size of the market and satisfy the inequality $g<4 \bar{c} / A<4$.

${ }^{8}$ Recall that the feasible parameter values are $(g, \Phi) \in(0,4) \times\left(0, \frac{1}{3}\right]$.
} 


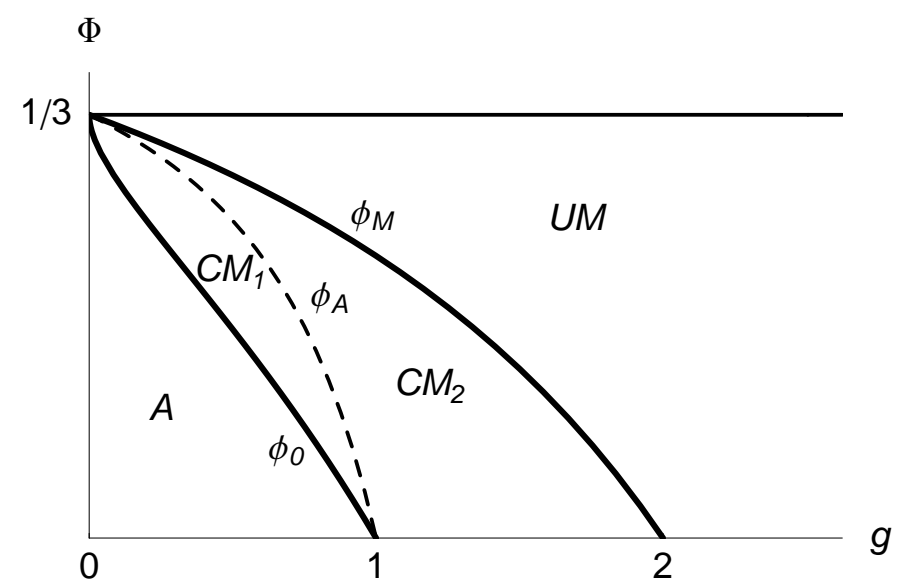

Figure 1: Leader's optimal strategies in the static model (parameter values $A=5, c=4$ )

\section{Dynamic Model}

Building upon the static model, we consider a setup in which all firms may operate over an infinite time horizon (in continuous time). Much like in the static setup, we assume that there is one leader firm (indexed by 0 ), and several potential follower firms indexed by $i=1,2, \ldots$. Note that now each active firm needs to incur the production costs at each moment of time. These costs comprise of instantaneous fixed costs $F$ and unit (variable) $\operatorname{costs} c$. We assume that initially (at time $t=0$ ), all firms are identical and have unit costs $c_{0}(0)=c_{i}(0)=\bar{c}$. The leader makes an investment that affects its unit costs; the followers make no investment and their unit costs are constant over time, i.e., $c_{i}(t)=\bar{c}$ for all $t \geq 0$.

In order to build a genuine dynamic model, we now consider a law of motion that drives the change in the leader's unit costs, depending on its investment. Denoting the time path of the leader's investment as $x(t)=z^{2}(t)$ (where $z(t) \geq 0$ ), we assume that its unit costs change according to the following law of motion

$$
\dot{c}_{0}(t)=\mu\left[\bar{c}-c_{0}(t)-\sqrt{g} z(t)\right]
$$

that resembles specification (4) of the static model in Section 2.2. In particular, we assume that it takes time for the R\&D investment to transform into a decrease in unit costs and we introduce the speed of adjustment parameter $\mu>0$ designed to capture this time lag (more precisely, the inverse of it). In this respect our model closely follows that of Stenbacka and Tombak (1997); see also Fershtman and Kamien (1987) for a similar approach. ${ }^{9}$ The parameter $g$ characterizes the efficiency of the R\&D process; we assume that $g \in(0,4 \rho)$ where $\rho=1+r / \mu \geq 1$, due to the requirement for monopoly output and

\footnotetext{
${ }^{9}$ Kobayashi (2001) made a differential game version of the D'Aspremont and Jacquemin (1988) twostage game, where the dynamics of the model stems from a depreciation of $R \& D$ stock rather than from the speed of adjustment.
} 
investment to be positive in the dynamic context (see Section 5.3). The expression $\rho-1$ can then be viewed as a so-called "generalized discount rate", that is, the interest rate $r$ corrected by the speed-of-adjustment coefficient: Given $r$, the higher the level of $\mu$, the faster R\&D investment materializes, and the more important the future becomes. The parameter $\rho$ will turn out as particularly relevant for the leader's intertemporal decisions.

Note that the above law of motion requires sufficient perpetual investments in order to prevent the unit costs from increasing. If the investment is not sufficient, the costs tend to revert back to their initial value $\bar{c}$. In particular, in the absence of $\mathrm{R} \& \mathrm{D}$ investment, the costs will converge to $\bar{c}$ when $t \rightarrow \infty$. The latter can be interpreted as some kind of depreciation of knowledge or skills. ${ }^{10}$

Given the leader's unit costs $c_{0}(t)$ as a state variable, at each point in time the market follows the equilibrium with endogenous entry (see Section 2.1), where the number of active followers as well as the leader's output adjust instantaneously. Note that only the leader's investment decision involves intertemporal trade-offs. In this respect, the explicit dynamics in the model comes from the leader's intertemporal R\&D investment decision and not from the competition in quantities. The latter is myopic in nature since both the leader and the followers determine their outputs via Cournot-Nash equilibrium at each instant of time rather than committing in advance to a particular output path. These instantaneous equilibria are however critically determined by the R\&D flow that the leader has under its control. Our approach is thus in a sense a generalization of the related static models at which the $R \& D$ of the leader at an initial stage of the game affects the output and number of firms at subsequent stages of the game.

As for the number of followers, $n=n(t)$ is now a time-specific variable and it is determined by the law of motion of the unit costs. The intuition for it is that a change in production technology and the speed of its adoption are key factors governing the change in the efficiency of the technological leader and through this it affects the dynamics of new firms' entry into the market. Consistent with this, the change of unit costs and its speed (aimed to capture the change and dynamics of technology improvement) fully determines the number of firms and their dynamics in our model. The dynamics (law of motion) for the number of firms and the leader's output can be derived from the equilibrium relations (1) and (2) by taking their time derivatives, $\dot{n}(t)=\frac{1}{\sqrt{F}} \dot{c}_{0}(t)$ and $\dot{q}_{0}(t)=-\dot{c}_{0}(t)$. After substituting for $c_{0}$ and $\dot{c}_{0}$ into the law of motion (6) we obtain:

$$
\begin{aligned}
\dot{n}(t) & =\mu\left[\frac{A-\bar{c}-2 \sqrt{F}}{\sqrt{F}}-n(t)-\frac{\sqrt{g}}{\sqrt{F}} z(t)\right], \\
\dot{q}_{0}(t) & =\mu\left[\sqrt{F}-q_{0}(t)+\sqrt{g} z(t)\right],
\end{aligned}
$$

whenever entry occurs, that is, $n(t)>1$. Since all firms are identical at time $t=0$

\footnotetext{
${ }^{10}$ The expression $\mu\left[\bar{c}-c_{0}(t)\right]$ then corresponds to the instantaneous depreciation rate.
} 
(i.e., $c_{0}(0)=c_{i}(0)=\bar{c}$ for all $i$ ), it follows from (1) and (2) that the initial leader's equilibrium output is evaluated as $q_{0}(0)=\sqrt{F}$, and the initial number of followers equals $n(0)=\frac{1}{\Phi}-2$.

\subsection{Leader's Optimization Problem}

The leader maximizes the present value of its (net) profit and solves the following infinite horizon optimal control problem with one state variable $c_{0}$ and one control variable $z$ :

$$
\begin{aligned}
& \max _{z(\cdot)} \int_{0}^{\infty}\left[q^{2}(t)-z^{2}(t)-F\right] e^{-r t} d t \\
& \text { subject to } \\
& \dot{c}_{0}(t)=\mu\left[\bar{c}-c_{0}(t)-\sqrt{g} z(t)\right], \\
& q(t)= \begin{cases}q_{0}(t), & \text { if } c_{0}(t)>\hat{c} \\
q_{M}(t), & \text { if } c_{0}(t) \leq \hat{c}\end{cases} \\
& c_{0}(0)=\bar{c} \text {. }
\end{aligned}
$$

This problem involves a "regime change" that occurs when the leader's costs attain the critical value $\hat{c}=-A+2 \bar{c}+3 \sqrt{F}$. If the leader's costs are above $\hat{c}$, at least one follower is active, and the leader's output equals $q_{0}(t)=\bar{c}+\sqrt{F}-c_{0}(t)$ as in the equilibrium with endogenous entry. If the leader's costs fall below the critical value, it becomes a monopolist producing output $q_{M}(t)=\frac{1}{2}\left[A-c_{0}(t)\right]$.

There are several points worth noting. First, the leader's optimization problem does not explicitly contain the number of followers, which is, however, endogenous and follows the law of motion (7). Second, fixed costs $F$ in the leader's objective function are incurred over the whole time span (and integrate up to $F / r$ ) independently from the leader's investment decision, and thus can be in principle omitted. However, for the sake of completeness we will always include them in the objective function. Third, the leader always has the option not to invest at all, in which case it will be identical to the followers and earn zero profit. Finally, initially there is always at least one active entrant, because $\bar{c}>\hat{c}$ (or, equivalently, $\Phi<\frac{1}{3}$ ). However, the current number of active followers is neither bounded from above nor assumed to be strictly positive, and depends on the exogenously given parameters $A, \bar{c}, F$ and $g$, and on the endogenously determined investment strategy $z(t)$ (in particular, $n(t)$ does not change if $n(t)=\frac{1}{\Phi}-2-\frac{\sqrt{g}}{\sqrt{F}} z(t)$ ).

Depending on whether the leader eventually becomes a monopolist, we classify its strategies into the following two categories:

1. Accommodation: The leader invests only moderately in $R \& D$ so that at least one active follower exists at any point in time, i.e., $n(t)>1$ for all $t \geq 0$. In this case, the leader's costs always lie above the threshold $\hat{c}$. 
2. Strategic predation: The leader invests significantly in $R \& D$ in order to eventually eliminate all followers and achieve a monopoly position, i.e., $n(T)=1$ at a finite point in time $T$. In this case, the leader's costs attain the critical value $\hat{c}$ at time $T$.

Note that accommodation may also involve the elimination of some (but not all) followers. According to our classification, in accommodation there is at least one active follower at any point in time.

It is important to recognize that in the case of strategic predation, insufficient $R \& D$ investment may in principle result in the eventual reversal of the leader's costs to the critical level $\hat{c}$ and even above it, allowing some of the followers to re-enter the market. However, such a pattern is never optimal because the problem involves an unbounded time interval, and, therefore, the problem is "shift invariant", i.e., the optimal value of control $z$ depends directly only on the state $c_{0}$ and not on the physical time $t .{ }^{11}$ Thus, if the leader's unit costs attain the same value at two distinct points in time, the subsequent investment patterns in both cases should be identical. The latter excludes the possibility that (under optimal investment) the leader's costs revert back to the value $\hat{c}$ once they are lower than $\hat{c}^{12}$ Of course, the same argument holds for any value of costs, which means that the leader's costs are non-increasing in optimum. Moreover, if the leader's costs stay constant over a certain time interval, then they also remain unchanged afterwards. The above argument also implies that in optimum, the leader's output is non-decreasing and its $R \& D$ investment is always positive.

Compared to the static model, the time dimension enriches the set of strategies available to the leader. In particular, in the case of strategic predation, the leader's investment decision determines the predation time $T$ when all followers are eliminated. Similarly to the static model, we solve the problem by separately considering the case of accommodation and the case of strategic predation. Under each strategy we find an optimal investment pattern. Further, we find conditions under which these patterns are sustainable and compare the leader's profits in cases when more strategies are sustainable.

\section{Accommodation}

Let us first consider the leader's optimization problem under the accommodation strategy. In that case, $q(t)=q_{0}(t)=\bar{c}+\sqrt{F}-c_{0}(t)$ for all $t \geq 0$. Thus, we may rewrite the problem

\footnotetext{
${ }^{11}$ Note that our problem is indeed shift invariant despite the objective function being time dependent. This follows from linearity and from the specific time dependence in the form of discounting.

${ }^{12}$ Reverting would mean that for some $\varepsilon$, the value $\hat{c}-\varepsilon$ is also attained at two points in time, followed one time by a decrease and the other time by an increase in the leader's costs.
} 
$(L)$ in terms of the leader's quantity $q$ as a state variable following the law of motion (8):

$$
\begin{array}{r}
I_{A}=\max _{z(\cdot)} \int_{0}^{+\infty}\left[q^{2}(t)-z^{2}(t)-F\right] e^{-r t} d t, \\
\text { subject to } \\
\dot{q}(t)=\mu[\sqrt{F}-q(t)+\sqrt{g} z(t)], \\
q(0)=\sqrt{F} .
\end{array}
$$

In order to solve this problem, we form the Hamiltonian function

$$
\mathcal{H}=\left(q^{2}-z^{2}-F\right) e^{-r t}+\eta \mu(\sqrt{F}-q+\sqrt{g} z)
$$

where $\eta$ is a Lagrange multiplier. The joint dynamics of the state and control variables is derived from the first-order conditions (see the Appendix for details) ${ }^{13}$

$$
\begin{aligned}
& \dot{z}=(r+\mu) z-\mu \sqrt{g} q, \\
& \dot{q}=\mu(\sqrt{F}+\sqrt{g} z-q) .
\end{aligned}
$$

System (10)-(11) has a unique equilibrium (steady-state):

$$
z_{A}^{*}=\frac{\mu \sqrt{g F}}{r+\mu(1-g)}=\frac{\sqrt{g}}{\rho-g} \sqrt{F}, \quad q_{A}^{*}=\frac{(r+\mu) \sqrt{F}}{r+\mu(1-g)}=\frac{\rho}{\rho-g} \sqrt{F}
$$

with the steady-state number of followers and the leader's unit costs

$$
n^{*}=\frac{1}{\Phi}-\frac{2 \rho-g}{\rho-g} \quad \text { and } \quad c_{A}^{*}=\bar{c}-\frac{g}{\rho-g} \sqrt{F} .
$$

Since $z(t)$ must be non-negative, the equilibrium may arise only in the first quadrant (i.e., $z_{A}^{*} \geq 0, q_{A}^{*} \geq 0$ ). Therefore, the equilibrium exists if and only if $r+\mu(1-g)>0$, or $g<\rho$. The above method solves the leader's optimization problem in accommodation as an unconstrained optimization problem. We, however, also need to verify that the leader's unit costs indeed always remain above the critical value $\hat{c}$, or equivalently that its output does not fall below $\hat{q}_{0}=A-\bar{c}-2 \sqrt{F}$. In such a case we say that accommodation is sustainable. By the same argument as in the previous section, the leader's unit costs are non-increasing over time under the optimal investment path. Thus, the condition for sustainability reduces to a simple check of whether the steady-state is sustainable; formally, $c_{A}^{*} \geq \hat{c}$ (or $q_{A}^{*} \leq \hat{q}_{0}$ ). To this end, the sustainability condition for accommodation

\footnotetext{
${ }^{13}$ Alternatively, the solution can be obtained by making a transformation of $(A)$ as $\tilde{q}=e^{-\frac{1}{2} r t} q_{0}$, $\tilde{z}=e^{-\frac{1}{2} r t} z$ that brings the problem into a standard linear quadratic form, which can be solved using Theorem 5.16 in Engwerda (2005).
} 
becomes

$$
g<\rho \quad \text { and } \quad \Phi \leq \phi_{A}(g)=\frac{\rho-g}{3 \rho-2 g}
$$

Much like in the static model, the function $\phi_{A}$ is decreasing and, thus, inequality (13) is satisfied when $g$ is sufficiently low. In other words, accommodation is sustainable only if $R \& D$ efficiency is not very high.

It is worthwhile to note that the steady-state value of investment monotonically increases, and the steady-state number of followers monotonically decreases in $\mu$. Moreover, when the adjustment becomes instantaneous $(\mu \rightarrow \infty)$, the steady-state values of all variables coincide with their static counterparts. Also, condition (13) reduces to the sustainability condition in the static model. Thus, the static model serves as a good long-run approximation of the dynamic one for industries that are subject to rapid technological change. However, when the speed of adjustment becomes smaller, we may expect lower investments as well as a higher number of firms in the long run.

If $g<\rho$, then the eigenvalues of the system (10)-(11) are real and of opposite sign (i.e., the equilibrium is a saddle). The existence of a unique equilibrium then implies the existence and uniqueness of an optimal path of $R \& D$ and output converging to this equilibrium. Using the initial condition together with the transversality condition, it is straightforward to obtain the following closed-form solution for the joint dynamics of R\&D investment and output (see the Appendix for technical details and Figure 2 for an illustration):

$$
\begin{aligned}
& z_{A}(t)=z_{A}^{*}-\frac{g}{\rho-g} \sqrt{F} \cdot \frac{\rho+1-\sqrt{(\rho+1)^{2}-4 g}}{2 \sqrt{g}} e^{\lambda_{A} t}, \\
& q_{A}(t)=q_{A}^{*}-\frac{g}{\rho-g} \sqrt{F} e^{\lambda_{A} t}
\end{aligned}
$$

where $\lambda_{A}=\frac{1}{2}\left[\rho-1-\sqrt{(\rho+1)^{2}-4 g}\right] \mu$ is the negative eigenvalue of the system (10)(11). The price is constant over time and equals $\bar{c}+\sqrt{F}$, which is the equilibrium price (see Section 2.1), independent on the leader's unit costs. Note that the optimal R\&D investment (14) as well as the leader's output monotonically increase over time towards its steady-state value. Higher values of $\mu$ are associated with a higher steady-state value of investments and faster convergence towards the steady-state (i.e., higher absolute value of $\left.\lambda_{A}\right) .{ }^{14}$ The intuition is that a higher rate of transformation of R\&D inputs into lower unit costs (higher $\mu$ ) decreases the time gap between the R\&D investment and its benefits expressed in terms of future profits. If adjustment takes place instantaneously $(\mu \rightarrow \infty)$, then $q(t) \equiv q_{A}^{*}$ and $z(t) \equiv z_{A}^{*}$, as predicted by the static model.

\footnotetext{
${ }^{14}$ Note that due to the condition $g<\rho=1+\frac{r}{\mu}$, the inequality $g<1$ is necessary in order to have the set of feasible values of $\mu$ unbounded.
} 
Now it is technically possible to evaluate the leader's maximal profit in closed form as $I_{A}=\int_{0}^{\infty}\left[q_{A}^{2}(t)-z_{A}^{2}(t)-F\right] e^{-r t} d t$. The resulting expression is, however, rather complicated and will not be provided here. As a special case note that if the adjustment is instantaneous, the leader's maximal profit becomes $\int_{0}^{\infty}\left[\left(q_{A}^{*}\right)^{2}-\left(z_{A}^{*}\right)^{2}-F\right] e^{-r t} d t=$ $\frac{1}{r}\left[\left(q_{A}^{*}\right)^{2}-\left(z_{A}^{*}\right)^{2}-F\right]=\frac{g}{(1-g) r} F$. Note also that, unlike in the case of an exogenously given number of followers, the leader's profit increases in the fixed costs $F$, because larger $F$ leads to less entry and thus enables the leader to enjoy a higher profit.
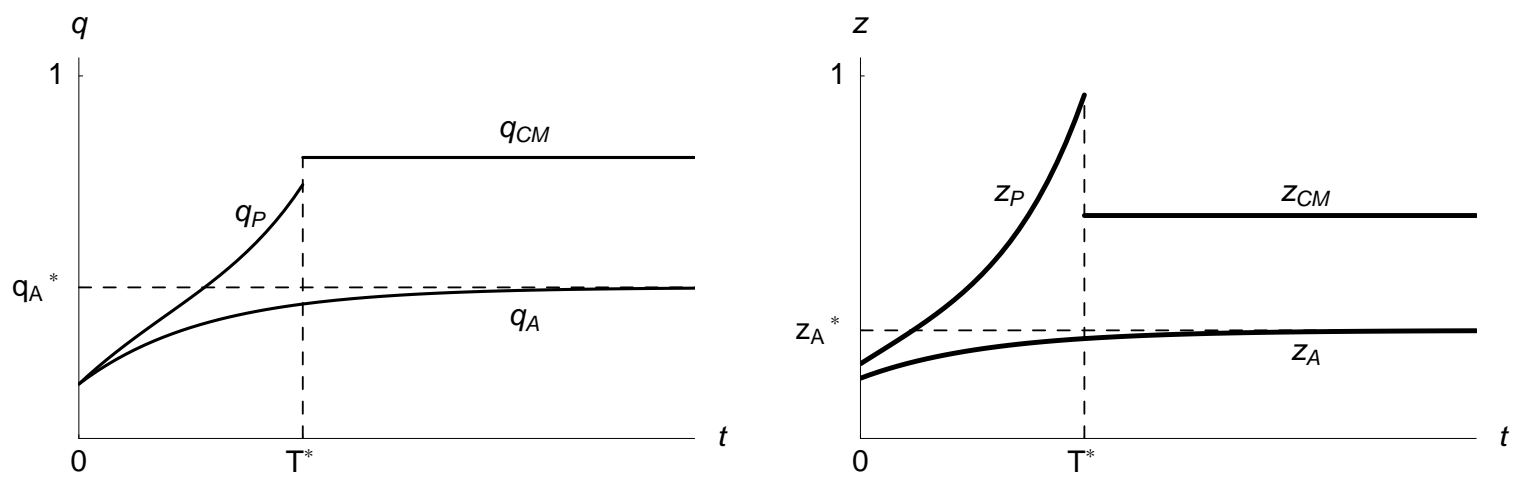

Figure 2: Patterns of $q$ and $z$ in accommodation and strategic predation (example for $A=5, c=4, r=0.05, g=0.8, F=0.0225, \mu=0.2$; which implies $\Phi=0.15, \rho=1.25)$

\section{$5 \quad$ Strategic Predation}

Strategic predation involves two phases. In the first phase, the predation phase, the leader invests in $R \& D$ in order to gradually decrease the number of followers. If it aims to eliminate the followers rather early, it may even incur temporary losses. When the leader's costs eventually fall to the level $\hat{c}$ at time $T$, it becomes a monopolist. In the second phase, the monopoly phase, the leader enjoys the monopoly position. At time $T$, the leader faces two options. First, it may decide to keep its unit costs at the level $\hat{c}$ that will just prevent the follower(s) from entering the market. ${ }^{15}$ In such a case, the leader is constrained by the presence of potential followers and we call the resulting arrangement a constrained monopoly. Second, the leader may continue to lower its costs further. In this case the leader won't be constrained by the presence of potential followers anymore; we call this arrangement an unconstrained monopoly. Recall that in Section 3.1 we argued that the leader's unit costs are non-increasing in optimum. Thus, it is not optimal for the leader to allow the re-entry of followers after having achieved the monopoly position. This way persistence of monopoly arises endogenously, due to enduring investments in

\footnotetext{
${ }^{15}$ When $c_{0}(t)=\hat{c}$, there is actually only one active follower. However, as we argued in footnote 6 , by slightly increasing investment, the leader gains a monopolistic position, which raises its profit significantly (due to the jump upwards). Thus, in the equilibrium, the leader will become a monopolist even with $c_{0}(t)=\hat{c}$.
} 
R\&D that do not vanish once the leader has achieved the monopoly position. Note also that in both the constrained and the unconstrained monopoly, the leader indeed chooses the monopoly output given its current costs. Thus, the concept of "constrained" rather applies to whether its investment decision is affected by the presence of potential followers.

We find the optimal investment path under strategic predation in three steps:

1. We solve the predation phase. Given the predation time $T$, we find the optimal path of $\mathrm{R} \& \mathrm{D}$ on the interval $[0, T]$ that leads to the elimination of all followers by time $T$. Let $I_{P}(T)$ denote the corresponding present value of the leader's profit.

2. We solve the monopoly phase. Given that all followers are eliminated at time $T$, we find the optimal path of R\&D on the interval $[T, \infty)$ under unconstrained as well as constrained monopoly. Let $I_{M}(T)$ and $I_{C M}(T)$ denote the corresponding present values of profits (evaluated at time $T$ ).

3. We maximize profits $I_{P}(T)+e^{-r T} I_{M}(T)$ and $I_{P}(T)+e^{-r T} I_{C M}(T)$ with respect to the predation time $T$.

\section{$5.1 \quad$ Predation Phase}

In this section we solve for the first step of the optimization problem listed above. If the leader firm sets the objective to eliminate all its rivals at time $T$, its output should attain the critical value $\hat{q}_{0}=A-\bar{c}-2 \sqrt{F}$ at time $T$, whereas the market is in equilibrium with endogenous entry before time $T$. This imposes an additional terminal condition on the leader's output. The leader thus solves the following optimization problem:

$$
\begin{array}{r}
I_{P}(T)=\max _{z(\cdot)} \int_{0}^{T}\left[q^{2}(t)-z^{2}(t)-F\right] e^{-r t} d t, \\
\text { subject to } \\
\dot{q}(t)=\mu[\sqrt{F}-q(t)+\sqrt{g} z(t)], \\
q(0)=\sqrt{F}, \quad q(T)=A-\bar{c}-2 \sqrt{F} .
\end{array}
$$

The problem $(P)$ is indeed very similar to $(A)$; it differs only in the additional terminal condition $q(T)=\hat{q}_{0}=A-\bar{c}-2 \sqrt{F}$ at time $T$, that is equivalent to $c_{0}(T)=\hat{c}$, or $n(T)=1$. Thus, we again obtain Hamiltonian (9) and equations (10)-(11) that drive the joint dynamics of $R \& D$ and output. However, instead of applying the transversality condition, we use the terminal condition to solve these equations; see the Appendix for details as well as the closed-form solution. Figure 2 illustrates the optimal dynamics of $q$ and $z$ in predation. Note that Figure 2 presents the case when the leader indeed makes 
instantaneous losses during the predation phase, because its gross profit does not cover the R\&D investments whenever $q_{P}(t)<z_{P}(t)$.

Similarly to the accommodation case, we can then evaluate the optimal profit $I_{P}(T)$ associated with the predation phase that lasts up to a given time $T$, as $I_{P}(T)=\int_{0}^{T}\left[q_{P}^{2}(t)-\right.$ $\left.z_{P}^{2}(t)-F\right] e^{-r t} d t$. Again, we will not provide the explicit formula; it can be easily computed from the solution in the Appendix. Note, however, that with instantaneous adjustment $(\mu \rightarrow \infty)$, the optimal predation profit becomes similar to the one from the accommodation case $\int_{0}^{T}\left[\left(q_{A}^{*}\right)^{2}-\left(z_{A}^{*}\right)^{2}-F\right] e^{-r t} d t=\frac{1}{r}\left(1-e^{-r T}\right)\left[\left(q_{A}^{*}\right)^{2}-\left(z_{A}^{*}\right)^{2}-F\right]=\frac{g}{(1-g) r}\left(1-e^{-r T}\right) F$.

Let us now study comparative dynamics of the leader's optimal investment path. In addition to the comparisons with respect to $\mu$, as in the preceding section, we are interested in the comparative results with respect to predation time $T$. Such results then help us to assess properties of the overall profit with respect to $T$.

Intuitively, if the speed of adjustment $\mu$ increases, predation becomes easier and requires lower investment. Thus, we might expect the profit from predation to be increasing in $\mu$. Similarly, an increase in predation time $T$ should lead to a lower investment and a lower output, which consequently increases profit. When the predation time becomes very long, the leader's behavior in predation should be close to that in accommodation. This, in particular, means that in the predation phase the leader indeed invests more than in accommodation.

The above intuition as well as the additional comparative dynamics results are summarized in the two lemmas below.

Lemma 1. Assume that accommodation is sustainable, i.e., $\Phi<\phi_{A}(g)$. Then, $z_{P}(t)$ and $q_{P}(t)$ are increasing over time, but are decreasing in the predation time $T$ and converge pointwise to $z_{A}(t)$ and $q_{A}(t)$ as $T \rightarrow \infty$.

Proof. See the Appendix.

In the following lemma we provide comparative dynamics results for the optimal predation profit $I_{P}(T)$. In order to compute its derivative with respect to the predation time $T$, we use the dynamic version of the Envelope theorem (see Theorem 10 in Seierstad and Sydsaeter, 1987, p. 213) which claims that:

$$
\frac{d}{d T} I_{P}(T)=\mathcal{H}^{*}(T)
$$

where $\mathcal{H}^{*}(T)$ is the Hamiltonian of the accommodation problem with predation time $T$, evaluated under optimal $q$ and $z$, and for $t=T$. This property turns out to be very handy in several places where we address the optimal predation time.

Lemma 2. Assume that accommodation is sustainable, i.e., $\Phi<\phi_{A}(g)$. Then the optimal profit from the predation phase $I_{P}(T)$ is increasing and concave in $T$, and converges to $I_{A}$ as $T \rightarrow \infty$. Moreover, $I_{P}(T)$ is increasing in the speed of adjustment $\mu$. 
Proof. See the Appendix.

\subsection{Constrained Monopoly}

In this section we search for the optimal investment path under a constrained monopoly. Assume that the leader's unit costs reach value $\hat{c}$ at time $T$ (i.e., all followers are eliminated by $T$ ) and the leader chooses to behave as a constrained monopolist. Thus, at time $T$, after the elimination of all followers the leader increases its output by $\frac{1}{2} \sqrt{F}$ to the monopoly quantity $q_{M}(T)=\hat{q}_{M}=A-\bar{c}-\frac{3}{2} \sqrt{F}$. At the same time the total output decreases by $\frac{1}{2} \sqrt{F}$ and the price increases by $\frac{1}{2} \sqrt{F}$ to the monopoly price $p_{M}(T)=\frac{1}{2}(A+\bar{c})=\bar{c}+\frac{3}{2} \sqrt{F}$.

After time $T$, the leader does not lower its costs below $\hat{c}$, but rather invests just as much as to keep its costs constant in order to prevent the followers from re-entering the market. As an outcome, the monopoly will persist over time. Setting $\dot{c}_{0}=0$ and $c_{0}=\hat{c}$ in the law of motion (6) we find that the investment and output are constant over time on $[T, \infty)$ and are equal to

$$
\begin{aligned}
& z_{C M}=\frac{A-\bar{c}-3 \sqrt{F}}{\sqrt{g}}, \\
& q_{C M}=\hat{q}_{M}=A-\bar{c}-\frac{3}{2} \sqrt{F} .
\end{aligned}
$$

The equations above represent a corner solution and are analogous to those in the static model case with $z=\hat{z}$. They indeed yield the same investment and output levels. Also note that the above path of $z$ and $q$ depends neither on the predation time $T$, nor on the speed of adjustment $\mu$. It is straightforward to verify that $z_{C M}>z_{A}^{*}$, which implies that in strategic predation with constrained monopoly the leader invests more than in accommodation, not only in the predation phase, but also after all rivals are eliminated.

The leader's profit $I_{C M}(T)$, evaluated at time $T$, also does not depend on the predation time $T$ and is equal to

$$
I_{C M}=\frac{q_{C M}^{2}-z_{C M}^{2}-F}{r} .
$$

Finally, let us find the optimal predation time $T$ that maximizes the overall profit $I_{P}(T)+e^{-r T} I_{C M}$. This problem represents the trade-off between incurring high costs in order to eliminate all followers early, or delaying high constrained monopoly profits when the followers are eliminated later. Recall that according to Lemma 2, the optimal profit from the predation phase is increasing in $T$. Early elimination (i.e., low $T$ ) leads to instantaneous losses (that is, negativity of instantaneous net profit) caused by high R\&D investments in the predation phase. These losses are compensated in the monopoly phase when all rivals are eliminated. On the other hand, when elimination is delayed (i.e., $T$ is 
high), the leader postpones the high profits earned in the constrained monopoly phase, but also invests only moderately in R\&D during the predation phase.

The optimal value of $T$ can be computed from the first order condition. Using (16), we obtain the derivative of the leader's overall profit

$$
\frac{d}{d T}\left[I_{P}(T)+e^{-r T} I_{C M}\right]=\mathcal{H}^{*}(T)-r e^{-r T} I_{C M}
$$

However, the resulting first order condition (with $T$ as unknown) is not solvable analytically (unless $\mu \rightarrow \infty$ ). Nevertheless, we are not directly interested in the magnitude of the leader's profit or the precise value of the predation time $T$, but in its choice between accommodation and strategic predation. Recall that when accommodation is sustainable, then $I_{P}(T) \rightarrow I_{A}$ as $T \rightarrow \infty$. Thus, also $I_{P}(T)+e^{-r T} I_{C M} \rightarrow I_{A}$ as $T \rightarrow \infty$. Thus, the leader chooses strategic predation over accommodation, if and only if $I_{P}(T)+e^{-r T} I_{C M}$ attains its maximum at a finite time $T$.

As an illustration, we analyze first the case of $\mu \rightarrow \infty$ (instantaneous adjustment). Then, the leader's profit from the predation strategy equals $\frac{1}{r}\left(1-e^{-r T}\right)\left[\left(q_{A}^{*}\right)^{2}-\left(z_{A}^{*}\right)^{2}-\right.$ $F]+\frac{1}{r} e^{-r T}\left[\left(q_{C M}^{*}\right)^{2}-\left(z_{C M}^{*}\right)^{2}-F\right]$. It increases in $T$ if $\left(q_{A}^{*}\right)^{2}-\left(z_{A}^{*}\right)^{2}>\left(q_{C M}^{*}\right)^{2}-\left(z_{C M}^{*}\right)^{2}$, and decreases in $T$ when the opposite inequality holds. In the former case, the leader's profit does not attain its maximum and the leader chooses accommodation. In the latter case, the optimal predation time is 0 ; the leader takes advantage of the instantaneous adjustment and eliminates all rivals immediately at $T=0$. In both cases, its profit then becomes identical to the static profit, except for the factor $\frac{1}{r}$, and the above inequality is actually equivalent to (5) in the static model.

In the general case of a finite $\mu$ we obtain the following proposition:

Proposition 1. The leader chooses accommodation over strategic predation with constrained monopoly, if and only if

$$
\left(1-\frac{3 \rho-2 g}{\rho-g} \Phi\right) \psi(g)>\sqrt{\Phi\left(1-\frac{7}{4} \Phi\right)},
$$

where $\psi(g)=\frac{1}{2 \sqrt{g}}\left[\rho-1+\sqrt{(\rho+1)^{2}-4 g}\right]>0$.

Proof. See the Appendix.

Inequality (19) holds if $\Phi=0$, and the opposite inequality is true if $\Phi=\phi_{A}(g)$. Similarly to the static case, we find that for any $g \in(0, \rho)$, there is a critical value of $\Phi$, denoted $\phi_{0}(g)$, such that the leader chooses accommodation if and only if $\Phi<\phi_{0}(g)$. This critical value is such that (19) holds with equality and satisfies the inequality $\phi_{0}(g)<$ $\phi_{A}(g)$ for all $g \in(0, \rho)$.

Consistently with the above analysis, (19) reduces to (5) when $\mu \rightarrow \infty$. In addition, the left-hand side of (19) is decreasing in $\mu$. Therefore, the size of the region where 
accommodation is chosen increases as $\mu$ decreases. This result is intuitive since lower values of $\mu$ make predation slower and more expensive.

\subsection{Unconstrained Monopoly}

Again, assume that the leader's unit costs become equal to the value $\hat{c}$ at time $T$, and the leader chooses to behave as an unconstrained monopolist by lowering its unit costs below $\hat{c}$. In that case, the leader can again set the monopoly quantity $q_{M}(t)=\frac{1}{2}\left[A-c_{0}(t)\right]$ after time $T$. Equation (6) implies that after time $T$, the leader's output follows the law of motion

$$
\dot{q}_{M}(t)=\mu\left[\frac{1}{2}(A-\bar{c})-q_{M}(t)+\frac{1}{2} \sqrt{g} z(t)\right]
$$

with the initial condition $q_{M}(T)=\hat{q}_{M}$. This initial condition is identical to that in the constrained monopoly case, and does not depend on time $T$. The law of motion and the leader's net (instantaneous) profit do not depend on $T$, either. Thus, the optimal path of investment after time $T$ does not depend on time $T$ itself. In other words, the leader's profit from unconstrained monopoly $I_{M}(T)$, evaluated at time $T$, also does not depend on $T$ and can be written as

$$
\begin{array}{r}
I_{M}=\max _{z(\cdot)} \int_{0}^{\infty}\left[q^{2}(t)-z^{2}(t)-F\right] e^{-r t} d t, \\
\text { subject to } \\
\dot{q}(t)=\mu\left[\frac{1}{2}(A-\bar{c})-q(t)+\frac{1}{2} \sqrt{g} z(t)\right], \\
q(0)=A-\bar{c}-\frac{3}{2} \sqrt{F} .
\end{array}
$$

Using a similar procedure as developed in Section 4 (see the Appendix for clarifications), we obtain a system of two differential equations analogous to (10)-(11). The equilibrium values of this system are derived as

$$
z_{M}^{*}=\frac{\sqrt{g}}{4 \rho-g}(A-\bar{c}), \quad q_{M}^{*}=\frac{2 \rho}{4 \rho-g}(A-\bar{c}) .
$$

Thus, we obtain the steady-state value of the leader's unit costs as

$$
c_{M}^{*}=\bar{c}-\frac{g}{4 \rho-g}(A-\bar{c}) .
$$

Recall that the set of values of $g$ has been restricted earlier to the interval $(0,4 \rho)$. The expression for $c_{M}^{*}$ provides a justification for such a restriction: It requires the monopoly 
output to be positive. ${ }^{16}$ Similarly to the accommodation problem, we also need to verify whether under the optimal investment path, the leader's costs do not exceed the critical value $\hat{c}$, which would lead to the re-entry of followers. In such a case, we again say that unconstrained monopoly is sustainable. The condition for sustainability thus becomes $c_{M}^{*} \leq \hat{c}$, or equivalently

$$
g<4 \rho \quad \text { and } \quad \Phi \geq \phi_{M}(g)=\frac{2(2 \rho-g)}{3(4 \rho-g)}
$$

Clearly, the function $\phi_{M}(g)$ is decreasing for $g \in(0,2 \rho)$, implying that unconstrained monopoly is sustainable only when the R\&D efficiency $g$ is sufficiently high. Moreover, as $\phi_{M}(g)>\phi_{A}(g)$ for all $g>0$, there are no values of parameters for which both accommodation and unconstrained monopoly are sustainable. In addition, as the investment path of constrained monopoly is available in the optimization problem $(M)$, the leader's profit from constrained monopoly cannot exceed the profit from unconstrained monopoly, whenever the latter is sustainable. It follows that unconstrained monopoly is optimal whenever it is sustainable. Last but not least, note that much like in the case of constrained monopoly, persistence of monopoly occurs here and is caused by the leader's $\mathrm{R} \& \mathrm{D}$ investment that persist even in the monopoly phase.

Finally, as in Section 4, we derive the joint dynamics of the leader's investments and output:

$$
\begin{aligned}
& z_{M}(t)=z_{M}^{*}+\left[\frac{2 \rho-g}{4 \rho-g}(A-\bar{c})-\frac{3}{2} \sqrt{F}\right] \frac{\rho+1-\sqrt{(\rho+1)^{2}-g}}{\sqrt{g}} e^{\lambda_{M} t}, \\
& q_{M}(t)=q_{M}^{*}+\left[\frac{2 \rho-g}{4 \rho-g}(A-\bar{c})-\frac{3}{2} \sqrt{F}\right] e^{\lambda_{M} t},
\end{aligned}
$$

where $\lambda_{M}=\frac{1}{2}\left[\rho-1-\sqrt{(\rho+1)^{2}-g}\right] \mu$. Note that the condition $g<4 \rho$ implies that $g<(\rho+1)^{2}$ and $\lambda_{M}<0$. The resulting price can then be computed as $p_{M}(t)=A-q_{M}(t)$. It follows from the sustainability condition that the $R \& D$ investment as well as the leader's output are increasing over time, whereas the price is decreasing. Interestingly, when the R\&D efficiency is sufficiently high, namely when $\Phi>\frac{3}{2} \phi_{M}(g)$, the leader keeps investing significantly in $\mathrm{R} \& \mathrm{D}$ so that the monopoly price eventually drops below the accommodation price, and in the steady-state $p_{M}^{*}<p_{A}$.

We can now evaluate the leader's profit $I_{M}=\int_{0}^{\infty}\left[q_{M}^{2}(t)-z_{M}^{2}(t)-F\right] e^{-r t} d t$. The optimal predation time $T$ can then be found as a maximum of the overall profit $I_{P}(T)+$ $e^{-r T} I_{M}$. Again, this optimization problem is solvable analytically only if $\mu \rightarrow \infty$. We omit further elaboration on the optimal predation time and the comparison to accommo-

\footnotetext{
${ }^{16}$ At this point we again need to mention that economic interpretation requires $c_{M}^{*}>0$, or equivalently $g<4 \rho \bar{c} / A$. By the same argument as in footnote 7 we again omit this condition from further elaborations.
} 
dation, because as shown above, the sustainability of unconstrained monopoly excludes the sustainability of accommodation.

\section{Accommodation vs. Strategic Predation}

In this section, we sum up on the leader's long-run strategies of accommodation and strategic predation. First, as argued above (see the preceding section), unconstrained monopoly is chosen by the leader whenever it is sustainable. Second, constrained monopoly is chosen when neither accommodation nor unconstrained monopoly are sustainable. Third, in some subsets of the region of parameters $(g, \Phi)$ where accommodation is sustainable, the leader prefers strategic predation with constrained monopoly in the second phase. More precisely, the set $(0,4 \rho) \times\left(0, \frac{1}{3}\right]$ of admissible values of $(g, \Phi)$ can be divided into four regions with the following market structures (see Figure 3 for an illustration):

- Region $U M$, where $\phi_{M}(g)<\Phi$ : Accommodation is not sustainable, but unconstrained monopoly is. Thus, strategic predation with unconstrained monopoly is optimal.

- Region $C M_{2}$, where $\phi_{A}(g)<\Phi<\phi_{M}(g)$ : Neither accommodation nor strategic predation with unconstrained monopoly are sustainable. Thus, strategic predation with constrained monopoly is optimal.

- Region $C M_{1}$, where $\phi_{0}(g)<\Phi<\phi_{A}(g)$ : Unconstrained monopoly is not sustainable, but accommodation is. It, however, yields a lower profit than strategic predation with constrained monopoly.

- Region $A$, where $\Phi<\phi_{0}(g)$ : Accommodation is sustainable and also optimal.

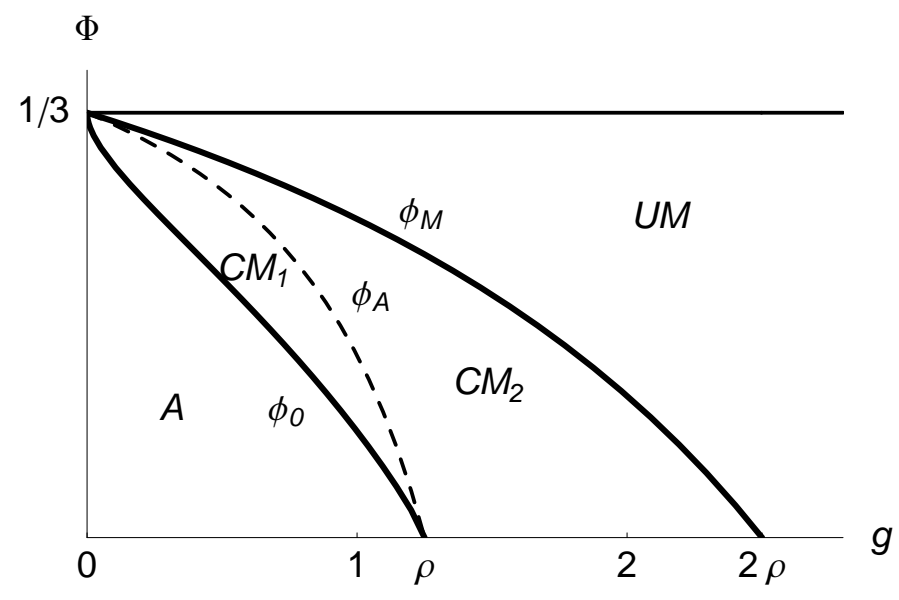

Figure 3: Leader's strategies in the dynamic model (for parameter values $A=5, c=4$, $r=0.05, \mu=0.2)$ 
As we have already mentioned, when the adjustment becomes instantaneous, these regions are identical to the ones found in the static model. On the contrary, when $\mu$ decreases (and, thus, $\rho$ increases) the curves $\Phi=\phi_{0}(g), \Phi=\phi_{A}(g)$ and $\Phi=\phi_{M}(g)$ rescale to the right (see Figure 3 ). This in particular means that region $A$ expands and accommodation becomes more likely when the rate of the adoption of new technologies is slower, whereas we might expect more predatory behavior in industries with rapid technological change. In our interpretation of $\rho-1$ as a generalized discount factor, the future becomes less important when $\rho$ increases. In turn, a heavily discounted future invites accommodation as a sustainable and also optimal long-run strategy. Thus, accommodation is more likely to become an optimal strategy in the equilibrium. The same effect arises when the discount rate $r$ increases which again implies that $\rho$ increases. In the limit case $r \rightarrow \infty$ we obtain that only accommodation is chosen by the leader (as the left-hand side of (19) diverges to $+\infty$ ).

At this point it is important to note that in all cases the equilibrium values of $q, z$, as well as prices are homogeneous of degree 1 in $(A-\bar{c}, \sqrt{F})$. Therefore, in all cases the equilibrium profits as well as consumer surplus, social welfare, and the present value of

R\&D investment are homogeneous of degree 2 in $(A-\bar{c}, \sqrt{F})$ and can be written as a product of $(A-\bar{c})^{2}$ and some function of $\Phi$ (that is independent on both $A$ and $\bar{c}$ ). Hence, any comparison of those variables does not depend on $A$ and $\bar{c}$; it can depend only on the parameters $g, \Phi, \mu$, and $r$.

\section{$7 \quad$ Welfare analysis}

In this section we analyze the normative aspects of the leader's strategies. That is, we compare the social welfare effects of strategic predation vis-à-vis accommodation and contrast them to an appropriate benchmark that involves the maximization of social welfare. An obvious benchmark would be the first-best situation, but this is not an overly interesting or insightful ground for comparison: in this case the government or social planner would clearly ban the entry of any followers in order to avoid the duplication of fixed costs and set a price equal to marginal costs (or to the average cost to make the firm break even). Thus, the only observed strategy would be the second phase of the predation strategy (note that it would be equivalent to the situation with optimal $T$ set equal to zero). Moreover, that first-best situation is in general not realistic and not achievable.

An alternative and, as we claim, more insightful benchmark would be a setup in which a social planner controls the leader's R\&D investments (and indirectly also the time of the elimination of the last follower, $T$ ) in order to maximize the social welfare, and does not interfere with the markets in any other way. In other words, the stage of the game 
in which the firms select quantities as well as the entry stage remain unaltered. We are particularly interested in the comparison of the choice of strategy (accommodation vs. strategic predation) by the leader as opposed to the corresponding choice of social planner. In the case of predation, we also compare the corresponding predation times.

Social welfare consists of firms' net profits and consumer surplus. In the case of linear demand considered here, the instantaneous consumer surplus has the simple form $C S=\frac{1}{2}(A-p)^{2}$, whereby the price $p$ depends on the market structure. Recall that accommodation as well as the predation phase of strategic predation exhibit (in equilibrium) the following two properties: (i) the price is constant and equal to $p_{A}=\bar{c}+\sqrt{F}$; (ii) all firms except the leader earn zero profit. Thus, the optimization problems of the leader and the social planner differ only by an additive constant, namely $C S_{A}=\frac{1}{2 r}\left(A-p_{A}\right)^{2}$, in the objective function. This implies that the leader's investment choice in accommodation coincides with the choice of social planner and is, therefore, socially efficient. Consequently, the output path is the same in both setups (given accommodation).

Now consider strategic predation with constrained monopoly after time $T$. If we fix the predation time $T$, by the same argument as above, the leader's investment choice in the predation phase is socially efficient. Moreover, in the second phase after time $T$, the investment path is uniquely determined (so that the unit costs remain equal to $\hat{c})$ and, therefore, the $\mathrm{R} \& \mathrm{D}$ expenditures are also socially efficient (given a constrained monopoly). The price is constant and equal to $p_{C M}=\bar{c}+\frac{3}{2} \sqrt{F}$, which is higher than $p_{A}$. Thus, the instantaneous consumer surplus in constrained monopoly is lower than in accommodation. Summing up, in both phases the objective function of the social planner differs from the leader's only in an additive constant and (given that predation is followed by constrained monopoly after time $T$ ) the social planner would undertake exactly the same R\&D investment over time, and consequently have the same output as the leader.

This efficiency argument, however, holds only for an exogenously given market structure (accommodation or constrained monopoly) and an exogenous (fixed) predation time $T$. Both market structures and predation time are part of the leader's decision process and are determined endogenously. Thus, for instance, the social planner may indeed prefer a different predation time than the leader as their maximization problems with respect to $T$ differ. The socially optimal predation time maximizes

$$
I_{P}(T)+e^{-r T} I_{C M}+\left(1-e^{-r T}\right) C S_{A}+e^{-r T} C S_{C M}
$$

where $C S_{C M}=\frac{1}{2 r}\left(A-p_{C M}\right)^{2}=\frac{1}{2 r} q_{C M}^{2}$, whereas the leader's objective function is merely $I_{P}(T)+e^{-r T} I_{C M}$.

Alike to the leader's problem, we can analyze the social planner's choice between accommodation and strategic predation with constrained monopoly by comparing the limiting behavior of her objective function $(22)$ as $T \rightarrow \infty$. We obtain the following 
proposition that is an analogue of Proposition 1.

Proposition 2. The social planner chooses accommodation over strategic predation with constrained monopoly, if and only if

$$
\left(1-\frac{3 \rho-2 g}{\rho-g} \Phi\right) \psi(g)>\sqrt{\frac{1}{2} \Phi\left(1-\frac{9}{4} \Phi\right)} .
$$

Moreover, in constrained monopoly, when $\Phi<\phi_{A}(g)$, the social planner chooses a longer predation time than the leader.

The above condition resembles very much the condition for the leader's choice in Proposition 1. They only differ in the right-hand sides, which is smaller in (23), meaning that the social planner chooses accommodation for a larger set of parameters. This, in turn, implies that there is a region where the leader's choice is socially inefficient, that is, (19) holds but (23) does not. This range of parameters represents a rather small region and is illustrated in Figure 4 by shading. Moreover, we again find that there exists a critical value of $\Phi$, denoted $\phi_{0 S}(g)$, such that the social planner chooses accommodation if and only if $\Phi<\phi_{0 S}(g)$. This critical value makes (23) an equality and satisfies $\phi_{0}(g)<\phi_{0 S}(g)<\phi_{A}(g)$ for all $g \in(0, \rho)$.

In other words, predation starts to become optimal when either R\&D efficiency gets larger ( $g$ rises), or the entry (fixed) costs increase relative to the size of the market (measured by $\Phi) .{ }^{17}$ Thus, these two factors make both the leader and the social planner more aggressive, tipping in favor of predation, and, hence, aimed for a larger profit and social welfare, respectively. The leader, however, ignores the impact of R\&D investment on consumer surplus and thus adopts predation for a bit lower combination of $g$ and $\Phi$ (see Figure 4). Regarding the social planner, the social gains from consumer surplus that comes from the followers' production still exceed the forgiven future profits from predation in the shaded region. So the social planner sticks to the accommodation strategy in this marginal range of parameters.

In the second part of Proposition 2, we claim that the leader would like to eliminate the followers earlier than is socially optimal. Thus, the leader overinvests in R\&D in order to achieve such a predation time. This also implies that during the predation period, the number of followers is smaller than would be socially optimal. Again, this is a consequence of the leader's ignorance of consumer surplus, making the leader more aggressive than is socially optimal.

Consider now predation with unconstrained monopoly. Recall that we keep the output choice unchanged, therefore the monopolist's output still satisfies $q(t)=A-p(t)=$ $\frac{1}{2}[A-c(t)]$. The corresponding consumer surplus then equals $C S(t)=\frac{1}{2} q^{2}(t)$. It is not

\footnotetext{
${ }^{17} \mathrm{~A}$ shift toward predation as an optimal strategy also occurs when, ceteris paribus, the rate of technology adoption $\mu$ increases, causing $\rho$ to fall.
} 
constant over time and causes a distortion in the optimization problem (compared to the leader's problem). As a consequence, the leader's R\&D investment would be socially suboptimal. The social planner solves a problem similar to $(M)$ but with the objective function being $\int_{0}^{\infty}\left[\frac{3}{2} q^{2}(t)-z^{2}(t)-F\right] e^{-r t} d t$. Solving the optimization problem (see the Appendix for details) we obtain the following sustainability condition:

$$
g<\frac{8}{3} \rho \quad \text { and } \quad \Phi>\phi_{M S}(g)=\frac{2(4 \rho-3 g)}{3(8 \rho-3 g)}
$$

Comparing the sustainability of unconstrained monopoly under the leader's and the social planner's optimal investments, we obtain that $\phi_{M S}(g)<\phi_{M}(g)$ for all $g \in\left(0, \frac{8}{3} \rho\right)$. Therefore, compared to the leader, the social planner is now more aggressive and chooses unconstrained monopoly for a larger set of parameters than the leader; see Figure 4 for an illustration. ${ }^{18}$ As before, the intuition behind this statement is that the social planner takes into account the positive impact of $\mathrm{R} \& \mathrm{D}$ on consumer surplus and, therefore, chooses a larger flow of R\&D than the profit-maximizing leader. For high enough $g$ and $\Phi$, this larger flow of R\&D prevents the followers to even control the firm's pricing policy via the threat of entry, enabling the social planner an unconstrained monopoly position. Consequently, the region of parameters where unconstrained monopoly is socially optimal becomes significantly larger compared to the respective set of parameters for the profit-maximizing leader. Moreover, the social planner's optimal choice implies higher steady-state output and a lower price (see the Appendix for details).

As for the optimal predation time when the predation phase is followed by an unconstrained monopoly, it appears that the social planner is again more aggressive and chooses a shorter $T$, provided that the R\&D efficiency $g$ and the relative size of the market $\Phi$ are large enough (see the Appendix for more details). In this case, the larger flow of R\&D by the social planner that acts as unconstrained monopolist generates both a bigger consumer surplus and a higher profit than any other market structure under consideration.

\section{Conclusion}

The empirical findings and stylized facts on the relations among innovation, technological leadership, and market power have motivated our paper to describe and analyze a particular setup with a technological leader and endogenous entry, where the persistence of monopoly is likely to arise in the long run. On the positive side, we study the

\footnotetext{
${ }^{18} \mathrm{It}$ appears that there is now a tiny region (not illustrated in the figure) where both accommodation and unconstrained monopoly are sustainable, that is $\phi_{M S}(g)<\phi_{A}(g)$ when $g \in\left(0, \frac{1}{3} \rho\right)$. However, in this region accommodation is inferior even to constrained monopoly. Thus, there is no point in making a cross-profit comparison of accommodation and strategic predation with unconstrained monopoly.
} 


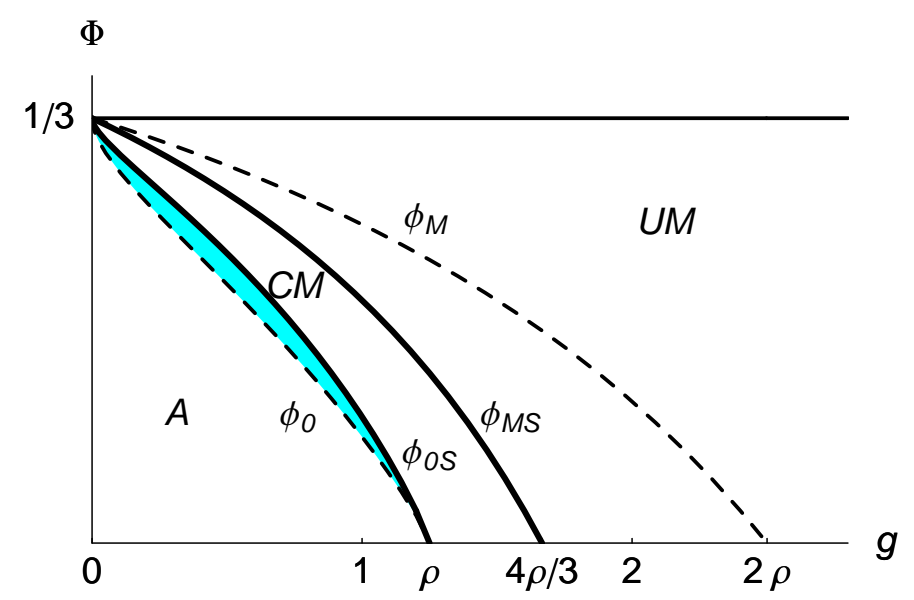

Figure 4: Socially efficient strategies in the dynamic model (for parameter values $A=5$, $c=4, r=0.05, \mu=0.2$ )

leader's choice between two main strategies of accommodation and strategic predation. On the normative side, we analyze the welfare aspects of the resulting market structures: oligopoly versus (constrained or unconstrained) monopoly. We show that strategic predation, when chosen by the leader, is in most cases also a socially efficient strategy.

Our analysis thus bears several important competition policy implications. First, the size of market share per se might not be a sufficient condition for a legal offence and, second, an abuse of a dominant position may not even be an issue in dynamic markets where competition takes place through investments in $\mathrm{R} \& \mathrm{D}$ rather than through static pricing, and where the very presence of actual or potential competitors constrains the behavior of market leaders. The challenge for the design of antitrust policy against predation is related to the ability of the antitrust authority to discriminate a price that is low for other predatory purposes from a price that might be set very low as a part of an efficiency-enhancing process, resulting, in turn, in enhanced competition and eventually leading not only to the exit of competitors but also to the enhancement of social welfare and, possibly, consumer surplus. For instance, in the presence of network effects or learning effects it would be legitimate and consistent with vigorous competition that firms set very low prices when they are introducing new products, targeting new customer segments or rivals, installed bases, or when they are in the first phase of the learning curve. Thus, a competition authority with limited knowledge of industry- and firmspecific data faces a complex problem when attempting to identify those circumstances under which loss-inducing predatory prices cause harm to the competition. For that reason the antitrust authorities have to be fully aware of the risks of misclassification when approaching a predation case.

Our results, however, are obtained under special modelling assumptions such as product homogeneity, endogenous entry, and a specific form of cost-reducing investment with exogenous speed of the adoption of new technology. Thus these results have to be taken 
with the necessary caveats. As we may know (e.g., from Dixit, 1979), product differentiation makes strategic predation more difficult and more costly for the leader. Moreover, strategic predation in this case leads to fewer product varieties in the market, and this in turn harms consumers. However, by the continuity argument, it is pretty safe to claim that our findings would also hold in the situation when the degree of product differentiation is not "large", that is, when the goods are "close" substitutes. We also assume an absence of entry barriers. If this is not the case then policy makers may worry about having only one firm in the market - recall, for instance, the relatively recent case of the banned merger of the General Electric and Honeywell. In the light of our analysis, however, the message would be that one should target barriers to entry rather than market leaders (see also Etro, 2006 in this respect). Another, possibly interesting, extension would be to allow for an exogenous exit rate of the followers in the spirit of Melitz (see, for instance, Ghironi and Melitz, 2005 and 2007 or Melitz and Ottaviano, 2007). Adding this feature to the model is likely to make strategic predation less costly and thus more attractive. In this case the leader would attain the monopoly position and display the persistence more often.

Furthermore, a natural way to generalize our model would be to consider other effects of investment. Despite the assumption of cost reducing investment, our results are not bound to this setup only. Our intuition is actually driven by the fact that investment increases the gap between the leader and the followers and results in less entry. Although the qualitative features may be different, our intuition translates to other setups where this property holds. Regarding the speed of adjustment, it could be "endogenized", for instance, as a function of the R\&D intensity or R\&D stock. But then, such endogenization may appear to make the leader even more aggressive - reinforcing our findings about the persistence of monopoly and strategic predation. Furthermore, we could model the last, quantity competition stage between the leader and follower explicitly by relying on the concepts of state-dependent strategies and Markov perfect equilibria. This approach could make the game even more "dynamic" and possibly provide further insights.

\section{A Appendix: Proofs and Derivations}

Solution to the optimal control problem $(A)$. The first-order conditions for the Hamiltonian (9) are:

$$
\begin{aligned}
& \mathcal{H}_{z}=-2 z e^{-r t}+\mu \sqrt{g} \eta=0, \\
& \mathcal{H}_{q}=2 q e^{-r t}-\mu \eta \quad=-\dot{\eta} .
\end{aligned}
$$

From the first condition, $\eta=\frac{2}{\mu \sqrt{g}} z e^{-r t}$, which after substitution into the second condition directly yields (10). Equation (11) is the law of motion. 
The eigenvalues and eigenvectors of the matrix associated with system (10)-(11) are $\lambda_{1,2}=\frac{\rho-1 \pm \sqrt{(\rho+1)^{2}-4 g}}{2} \mu, \quad V_{1,2}=\left(v_{1,2}, 1\right)^{T}=\left(\frac{\rho+1 \pm \sqrt{(\rho+1)^{2}-4 g}}{2 \sqrt{g}}, 1\right)^{T}$. If $g<\rho$, then the eigenvalues are real and of opposite sign and the equilibrium is a saddle, ${ }^{19}$ let $\lambda_{1}>0>\lambda_{2}$. Moreover, the system has a constant particular solution $\left(z_{A}^{*}, q_{A}^{*}\right)$. Thus, its general solution can be written as

$$
(z, q)^{T}=\left(z_{A}^{*}, q_{A}^{*}\right)^{T}+k_{1} V_{1} e^{\lambda_{1} t}+k_{2} V_{2} e^{\lambda_{2} t}
$$

where $k_{1}$ and $k_{2}$ are arbitrary constants.

The transversality condition demands $k_{1}=0$ (in other words, the optimal solution must be bounded). The constant $k_{2}$ is determined from the initial condition $q(0)=\sqrt{F}$, which implies $k_{2}=-\frac{g}{\rho-g} \sqrt{F}$. This gives the optimal path (14)-(15).

Solution to the optimal control problem $(P)$. As argued in Section 5.1, the solution is again of the form (24). Using the initial condition and the terminal conditions for the leader's output we solve for constants $k_{1}$ and $k_{2}$.

$$
\begin{aligned}
& k_{1}(T)=\frac{A-\bar{c}}{e^{\lambda_{1} T}-e^{\lambda_{2} T}}\left[\left(1-\frac{3 \rho-2 g}{\rho-g} \Phi\right)+\frac{g}{\rho-g} e^{\lambda_{2} T} \Phi\right], \\
& k_{2}(T)=\frac{A-\bar{c}}{e^{\lambda_{2} T}-e^{\lambda_{1} T}}\left[\left(1-\frac{3 \rho-2 g}{\rho-g} \Phi\right)+\frac{g}{\rho-g} e^{\lambda_{1} T} \Phi\right] .
\end{aligned}
$$

Recall that $k_{1}$ and $k_{2}$ are constant with respect to $t$, but depend on the predation time $T$. In further proofs we also use the argument $T$, and denote $z_{P}(t, T)$ and $q_{P}(t, T)$ the optimal paths of $z$ and $q$ in order to highlight their dependency on $T$.

Proof of Lemma 1. The monotonicity of $z$ and $q$ (with respect to $t$ ) can be established easily, when we recall that $\lambda_{1}>0>\lambda_{2}$. Then also $k_{1}>0>k_{2}$, whenever $\Phi<\phi_{A}(g)=$ $\frac{\rho-g}{3 \rho-2 g}$. Thus, both $k_{1}(T) e^{\lambda_{1} t}$ and $k_{2}(T) e^{\lambda_{2} t}$ are increasing in $t$. The monotonicity of $z$ and $q$ follows from the fact that eigenvectors $V_{1}$ and $V_{2}$ have positive coordinates.

Now we are in a position to study the comparative statics results with respect to the predation time $T$. The initial condition at time $t=0$ implies that $k_{1}(T)+k_{2}(T)=$ $\sqrt{F}-q_{A}^{*}$, which is constant. Taking the derivative, we obtain $k_{1}^{\prime}(T)+k_{2}^{\prime}(T)=0$. A direct computation gives

$$
k_{1}^{\prime}(T)=-\frac{A-\bar{c}}{\left(e^{\lambda_{1} T}-e^{\lambda_{2} T}\right)^{2}}\left[\left(\lambda_{1} e^{\lambda_{1} T}-\lambda_{2} e^{\lambda_{1} T}\right)\left(1-\frac{3 \rho-2 g}{\rho-g} \Phi\right)+\frac{g}{\rho-g}\left(\lambda_{1}-\lambda_{2}\right) e^{\left(\lambda_{1}+\lambda_{2}\right) T} \Phi\right],
$$

\footnotetext{
${ }^{19}$ If $\rho<g<\frac{1}{4}(\rho+1)^{2}$, the equilibrium is an unstable node. If $\frac{1}{4}(\rho+1)^{2}<g$, the equilibrium is an unstable focus.
} 
which is negative, given $\lambda_{1}>0>\lambda_{2}$. Therefore, $\frac{\partial}{\partial T} q_{P}(t, T)=\left(e^{\lambda_{1} t}-e^{\lambda_{2} t}\right) k_{1}^{\prime}(T)$ and $\frac{\partial}{\partial T} z_{P}(t, T)=\left(v_{1} e^{\lambda_{1} t}-v_{2} e^{\lambda_{2} t}\right) k_{1}^{\prime}(T)$. Since $\lambda_{1}>0>\lambda_{2}$ and $v_{1}>v_{2}$, both partial derivatives are clearly negative.

Taking the limit $T \rightarrow \infty$, we obtain $k_{1}(T) \rightarrow 0$ and $k_{2}(T) \rightarrow-\frac{g}{\rho-g} \sqrt{F}$, which are the same constants as in accommodation. Thus, $z_{P}(t, T)$ and $q_{P}(t, T)$ monotonically decrease and converge pointwise towards the values in accommodation $z_{A}(t)$ and $q_{A}(t)$ as $T \rightarrow \infty$.

Proof of Lemma 2. Assume $\Phi<\phi_{A}(g)$. The convergence with respect to $T$ follows from the direct evaluation of profits and from the convergence of coefficients $k_{1}$ and $k_{2}$ established in the proof of Lemma 1 (note that the instantaneous profit is actually a linear combination of exponential functions).

Now we prove the monotonicity with respect to $T$. Consider the Hamiltonian for the problem in accommodation. Substituting for the Lagrange multiplier $\eta$, we obtain the (present value) Hamiltonian along the optimal path:

$$
\mathcal{H}=\left(q^{2}+z^{2}-F-\frac{2}{\sqrt{g}} q z+\frac{2}{\sqrt{g}} \sqrt{F} z\right) e^{-r T} .
$$

Recall that both $q, z$, and also $\mathcal{H}$ are in fact functions of $t$ and $T$. In order to evaluate $\mathcal{H}^{*}(T)$ we need to substitute the terminal values of $z$ and $q$ at $t=T$. Recall that $q_{P}(T, T)=A-\bar{c}-2 \sqrt{F}=\hat{q}_{0}$ is constant, as given by the terminal condition for the predation phase. Let us now denote (the current value Hamiltonian)

$$
h(T)=\mathcal{H}^{*}(T) e^{r T}=z_{P}^{2}(T, T)-\frac{2}{\sqrt{g}}\left(\hat{q}_{0}-\sqrt{F}\right) z_{P}(T, T)+\hat{q}_{0}^{2}-F .
$$

As shown in the text preceding Lemma 2, the derivative of the leader's profit from the predation phase then equals $\frac{d}{d T} I_{P}(T)=\mathcal{H}^{*}(T)=h(T) e^{-r T}$. Moreover, $\frac{d^{2}}{d T^{2}} I_{P}(T)=$ $h^{\prime}(T) e^{-r T}-r h(T) e^{-r T}$. In the following we establish some properties of $h(T)$ :

(i) $\lim _{T \rightarrow 0^{+}} h(T)=+\infty$.

Proof. Given $v_{1}>v_{2}$ and $\lambda_{1}>0>\lambda_{2}$, we find that $\lim _{T \rightarrow 0^{+}} z_{P}(T, T)=+\infty$. Because $h(T)$ is quadratic in $z(T, T)$, then also $\lim _{T \rightarrow 0^{+}} h(T)=+\infty$.

(ii) $\lim _{T \rightarrow \infty} h(T)=(A-\bar{c})^{2}\left[\left(1-\frac{3 \rho-2 g}{\rho-g} \Phi\right)^{2} \psi^{2}(g)+(1-3 \Phi)(1-\Phi)-\frac{1}{g}(1-3 \Phi)^{2}\right]>0$, where $\psi(g)=\frac{1}{2 \sqrt{g}}\left[\rho-1+\sqrt{(\rho+1)^{2}-4 g}\right]>0$.

Proof. Denote $Y$ the expression in square brackets. It follows from (24) and (25)(26) that

$$
\lim _{T \rightarrow \infty} z_{P}(T, T)=z_{A}^{*}+\left[(A-\bar{c}-3 \sqrt{F})-\frac{g}{\rho-g} \sqrt{F}\right] \frac{\rho+1+\sqrt{(\rho+1)^{2}-4 g}}{2 \sqrt{g}} .
$$


The identity $\lim _{T \rightarrow \infty} h(T)=(A-\bar{c})^{2} Y$ is then obtained by a direct computation. To prove that $Y>0$, we discuss two cases. First consider the case $g \geq \frac{1-3 \Phi}{1-2 \Phi}$. As the first term in $Y$ is non-negative, then $Y \geq(1-3 \Phi)(1-\Phi)-\frac{1}{g}(1-3 \Phi)^{2}$. Using the above inequality for $g$, we obtain $Y \geq(1-3 \Phi)(1-\Phi)-(1-3 \Phi)(1-2 \Phi)=\Phi(1-3 \Phi)$, which is positive. Second, let $0<g<\frac{1-3 \Phi}{1-2 \Phi}$. Observe that this implies $g<1$. Now for any $\rho \geq 1$, we have $\rho>\frac{1-2 \Phi}{1-3 \Phi} g$, and thus $\Phi<\phi_{A}(g)$. For $\rho=1$ we obtain by a direct computation that $Y=\frac{g}{1-g} \Phi^{2}$, which is positive. As the last step, we show that $Y$ is increasing in $\rho$, when $\rho \geq 1$. This follows from the fact that both $\psi(g)$ as well as $1-\frac{3 \rho-2 g}{\rho-g} \Phi$ are positive and increasing in $\rho$.

(iii) $h^{\prime}(T)<0$ for all $T>0$.

Proof. Consider the derivative $h^{\prime}(T)=\frac{2}{\sqrt{g}}\left[\sqrt{g} z_{P}(T, T)-\hat{q}_{0}+\sqrt{F}\right] \frac{d}{d T} z_{P}(T, T)$. According to the law of motion, the term in brackets is actually the time derivative of the leader's output evaluated at time $t=T$, which is positive according to Lemma 1. Thus, it remains to prove that $\frac{d}{d T} z_{P}(T, T)<0$. This derivative is equal to

$$
\begin{aligned}
\frac{d}{d T} z_{P}(T, T)= & {\left[k_{1}^{\prime}(T)+\lambda_{1} k_{1}(T)\right] v_{1} e^{\lambda_{1} T}+\left[k_{2}^{\prime}(T)+\lambda_{2} k_{2}(T)\right] v_{2} e^{\lambda_{2} T}=} \\
= & {\left[k_{1}^{\prime}(T)+\lambda_{1} k_{1}(T)\right]\left(v_{1}-v_{2}\right) e^{\lambda_{1} T}=} \\
=- & \frac{e^{\left(\lambda_{1}+\lambda_{2}\right) T}(A-\bar{c})\left(v_{1}-v_{2}\right)}{\left(e^{\lambda_{1} T}-e^{\lambda_{2} T}\right)^{2}}\left[\left(\lambda_{1}-\lambda_{2}\right)\left(1-\frac{3 \rho-2 g}{\rho-g} \Phi\right)+\right. \\
& \left.\quad+\frac{g}{\rho-g}\left(\lambda_{1} e^{\lambda_{2} T}-\lambda_{2} e^{\lambda_{1} T}\right) \Phi\right],
\end{aligned}
$$

where the second line is obtained by differentiating the terminal condition $k_{1}(T) e^{\lambda_{1} T}+$ $k_{2}(T) e^{\lambda_{2} T}=\hat{q}_{0}-q_{A}^{*}$, which gives $\left[k_{2}^{\prime}(T)+\lambda_{2} k_{2}(T)\right] e^{\lambda_{2} T}=-\left[k_{1}^{\prime}(T)+\lambda_{1} k_{1}(T)\right] e^{\lambda_{1} T}$, and the third line comes by a direct computation. As $v_{1}>v_{2}, \lambda_{1}>0>\lambda_{2}$, and $\Phi<\phi_{A}(g)$, we indeed see that $\frac{d}{d T} z_{P}(T, T)<0$.

(iv) $h(T)>0$ for all $T>0$.

Proof. This follows directly from properties (ii) and (iii).

The monotonicity and concavity of $I_{P}(T)$ then follow from (iv) and (iii).

As the last part of the proof it remains to prove the monotonicity with respect to $\mu$. Here we make use of the Dynamic Envelope theorem by Caputo (1990). Similarly to the static envelope theorem, it specifies the (total) derivative of the optimal value of the objective functional with respect to a parameter. In our case,

$$
\frac{d}{d \mu} I_{P}(T)=\int_{0}^{T} \mathcal{L}_{\mu} d t
$$


where $\mathcal{L}$ is the Lagrangian of the problem. Note that in our problem the Lagrangian function coincides with the Hamiltonian. ${ }^{20}$ Because the parameter $\mu$ appears only in the law of motion, we obtain

$$
\frac{d}{d \mu} I_{P}(T)=\int_{0}^{T} \eta(t)[\sqrt{F}-q(t)-\sqrt{g} z(t)] e^{-r t} d t=\int_{0}^{T} \frac{2}{\mu \sqrt{g}} z(t) \dot{q}(t) e^{-r t} d t
$$

Since $z$ is non-negative, and it was already shown that $q$ is increasing, we conclude that $\frac{d}{d \mu} I_{P}(T)>0$.

Proof of Proposition 1. The derivative of the leader's overall profit takes the form

$$
\mathcal{H}^{*}(T)-r e^{-r T} I_{C M}=\left[h(T)-r I_{C M}\right] e^{-r T}
$$

As $h(T)$ is decreasing, the equation $h(T)=r I_{C M}$ may have at most one solution. Moreover, if such a solution exists (denote it as $T^{*}$ ), then the leader's profit is increasing on $\left(0, T^{*}\right)$ and decreasing on $\left(T^{*}, \infty\right)$, and, therefore, the leader prefers strategic predation (with the optimal predation time $T^{*}$ ) over accommodation. On the other hand, if the solution does not exist, then $h(T)>r I_{C M}$ for all $T \in(0, \infty)$, because $h(T)$ is not bounded from above as shown in property (i) in the proof of Lemma 2. Thus, the leader's profit is increasing in $T$ and the leader prefers accommodation over strategic predation.

In order to check whether the overall profit attains its maximum at finite $T$ it suffices to evaluate the sign of $h(T)-r I_{C M}$ in the limit, as $T \rightarrow \infty$. Recall that $r I_{C M}=$ $q_{C M}^{2}-z_{C M}^{2}-F$, where $z_{C M}$ and $q_{C M}$ are given by (17)-(18). This together with the property (iii) in the proof of Lemma 2 gives

$$
\lim _{T \rightarrow \infty} h(T)-r I_{C M}=(A-\bar{c})^{2}\left[\left(1-\frac{3 \rho-2 g}{\rho-g} \Phi\right)^{2} \psi^{2}(g)-\Phi\left(1-\frac{7}{4} \Phi\right)\right] .
$$

Since $\Phi<\frac{\rho-g}{3 \rho-2 g}<\frac{1}{3}$, the above limit is positive if and only if the condition stated in the proposition holds. This completes the proof.

As a byproduct, we can also compute the value of (instantaneous) investments at the optimal predation time. More precisely, by solving the quadratic equation $h(T)=r I_{C M}$ we obtain $z(T, T)=(A-\bar{c})\left[(1-3 \Phi) / \sqrt{g}+\sqrt{\Phi\left(1-\frac{4}{7} \Phi\right)}\right.$.

Solution to the optimal control problem $(M)$. The Hamiltonian for the problem becomes $\mathcal{H}=\left(q^{2}-z^{2}-F\right) e^{-r t}+\eta \mu\left[\frac{1}{2}(A-\bar{c})-q+\frac{1}{2} \sqrt{g} z\right]$, which yields the following differential equation for the control variable $\dot{z}=(r+\mu) z-\frac{1}{2} \mu \sqrt{g} q$. The solution follows directly

\footnotetext{
${ }^{20}$ Compared to the Hamiltonian, the Lagrangian contains additional terms for equality constraints multiplied by Lagrange multipliers.
} 
from the corresponding dynamic system by the same procedure as for the problem in accommodation.

Proof of Proposition 2. Similarly as in the proof of Proposition 1, we find that the derivative of social welfare with respect to $T$ is $\mathcal{H}^{*}(T)-r e^{-r T}\left(I_{C M}-C S_{A}+C S_{C M}\right)=$ $\left[h(T)-r I_{C M}+r\left(C S_{A}-C S_{C M}\right)\right] e^{-r T}$. Moreover, a straightforward computation gives

$$
\lim _{T \rightarrow \infty} h(T)-r I_{C M}+r\left(C S_{A}-C S_{C M}\right)=(A-\bar{c})^{2}\left[\left(1-\frac{3 \rho-2 g}{\rho-g} \Phi\right)^{2} \psi^{2}(g)-\frac{1}{2} \Phi\left(1-\frac{9}{4} \Phi\right)\right] .
$$

The condition stated in Proposition 2 now follows directly from this equality.

Furthermore, since $h(T)$ is decreasing and $C S_{A}>C S_{C M}$, the leader's first-order condition has a lower solution than the social planner's first-order condition.

Solution to the social planner's problem in unconstrained monopoly. As in Problem $(M)$, we obtain the Hamiltonian $\left(\frac{3}{2} q^{2}-z^{2}-F\right) e^{-r t}+\eta \mu\left[\frac{1}{2}(A-\bar{c})-q+\frac{1}{2} \sqrt{g} z\right]$ and thus the following differential equation describing the dynamics of the control variable: $\dot{z}=$ $(r+\mu) z-\frac{3}{4} \mu \sqrt{g} q$. The solution is again obtained directly from the corresponding dynamic system. In particular, the steady-state of the system is

$$
z_{M S}^{*}=\frac{3 \sqrt{g}}{8 \rho-3 g}(A-\bar{c}), \quad q_{M S}^{*}=\frac{4 \rho}{8 \rho-3 g}(A-\bar{c}) .
$$

Note that $z_{M}^{*}<z_{M S}^{*}$. Thus, in the steady-state, the leader underinvests, and also its output is lower than the social optimum.

The sustainability condition follows directly from the comparison of the steady-state value of the leader's $\operatorname{costs} c_{M S}^{*}=\bar{c}-\frac{3 g}{8 \rho-3 g}(A-\bar{c})$ with the critical value $\hat{c}^{21}$

To conclude, let us comment on the comparison of predation times. The social planner's optimal predation time maximizes the expression $I_{P}(T)+e^{-r T} I_{M S}+\left(1-e^{-r T}\right) C S_{A}+$ $e^{-r T} C S_{M S}$, where $I_{M S}=\int_{0}^{\infty}\left[q_{M S}^{2}-z_{M S}^{2}-F\right] e^{-r t} d t$ and $C S_{M S}=\frac{1}{2} \int_{0}^{\infty} q_{M S}^{2} e^{-r t} d t$ are the leader's profit and consumer surplus under the socially optimal investment, respectively. The derivative of social welfare is $\left[h(T)-r\left(I_{M S}-C S_{A}+C S_{M S}\right)\right] e^{-r T}$. Now, it can be easily shown that $I_{M S}-C S_{A}+C S_{M S}<I_{M}$, and also $I_{M S}-C S_{A}+C S_{M S}<I_{C M}$ for sufficiently large $g$. For decreasing $h(T)$, our result implies that the social planner chooses a shorter predation time than the leader. ${ }^{22}$

\footnotetext{
${ }^{21}$ Once more, an economic interpretation requires $c_{M S}^{*}>0$, or equivalently $g<\frac{8}{3} \rho \bar{c} / A$. See footnotes 7 and 16 for more details.

${ }^{22}$ Note however that $h(T)$ may not necessarily be decreasing outside the region where $\Phi<\phi_{A}(g)$ when $T$ is large. Thus, we have additionally verified the comparison of predation times in unconstrained monopoly numerically (using a grid of values of parameters $g$ and $\Phi$ in the range when unconstrained monopoly is feasible, and computing the optimal predation times for the values of $(g, \Phi)$ from that grid).
} 


\section{References}

[1] Aghion, P. and R. Griffith (2004). Competition and Growth, Cambridge, MA: The MIT Press.

[2] D'Aspremont, C. and A. Jacquemin (1988). "Cooperative and Noncooperative R\&D in Duopoly with Spillovers," American Economic Review, 78, 113-137.

[3] Blundell, R., R. Griffin, and J. van Reenen (1999). "Market Share, Market Value and Innovation in a Panel of British Manufacturing Firms," Review of Economic Studies, 66 (3), 529-554.

[4] Caputo, M. (1990). "How to Do Comparative Dynamics on the Back of an Envelope in Optimal Control Theory," Journal of Economic Dynamics and Control, 14 (3), 655-638.

[5] Carlin, W., M.E. Schaffer, and P. Seabright (2004). "A Minimum of Rivalry: Evidence from Transition Economies on the Importance of Competition on Innovation and Growth," CEPR Discussion Paper, No. 4343.

[6] Chin, J.C. and G.M. Grossman (1990). "Intellectual Property Rights and NorthSouth Trade," in R.W. Jones and A.O. Krueger (eds.), The Political Economy of International Trade: Essays in Honor of Robert E. Baldwin, Cambridge, MA: Basil Blackwell.

[7] Creane, A. and H. Konishi (2009). "The Unilateral Incentives for Technology Transfers: Predation (and Deterrence) by Proxy," International Journal of Industrial Organization, 27 (3), 379-389.

[8] Davidson, C. and A. Mukherjee (2008). "Horizontal mergers with free entry," International Journal of Industrial Organization, 25 (1), 157-172.

[9] Dixit, A. (1979). "A Model of Duopoly Suggesting a Theory of Entry Barriers," The Bell Journal of Economics, 10 (1), 20-32.

[10] Economist, The (2004). "Slackers or Pace-Setters: Monopolies May Have More Incentives to Innovate than Economists Have Thought," The Economist, May 20, 2004.

[11] Engwerda, J.C. (2005). LQ Dynamic Optimization and Differential Games, Chichester, UK: Wiley \& Sons.

[12] Erkal, N. and D. Piccinin (2007). "Welfare-Reducing Mergers in Differentiated Oligopolies with Free Entry," Mimeo, Intertic.

Available at: www.intertic.org/Theory\%20Papers/Erkal-Piccinin.pdf. 
[13] Etro, F. (2004). "Innovation by Leaders," The Economic Journal, 114 (485), 281303.

[14] Etro, F. (2006). "Aggressive Leaders," The Rand Journal of Economics, 37, 1-10.

[15] Etro, F. (2007). Competition, Innovation, and Antitrust: A Theory of Market Leaders and Its Policy Implications, Berlin: Springer.

[16] Fersthman, C. and M. Kamien (1987). "Dynamic Duopolistic Competition with Sticky Prices," Econometrica, 55 (5), 1151-1164.

[17] Fudenberg, D. and J. Tirole (1984). "The Fat-Cat Effect, the Puppy-Dog Ploy, and the Lean and Hungry Look," American Economic Review, 74 (2), 361-366.

[18] Ghironi, F. and M. Melitz (2005). "International Trade and Macroeconomic Dynamics with Heterogeneous Firms," Quarterly Journal of Economics, 120 (3), 865915.

[19] Ghironi, F. and M. Melitz (2007). "Trade Flow Dynamics with Heterogeneous Firms," American Economic Review Papers and Proceedings, 97 (2), 356-361.

[20] Kobayashi, S. (2001). "A Model of R and D in Oligopoly with Spillovers," Mimeo, Nihon University, Tokyo, Japan.

[21] Melitz, M. and M. Ottaviano (2008). "Market Size, Trade, and Productivity," Review of Economic Studies, 75 (1), 295-316.

[22] Seierstad, A. and K. Sydsaeter (1987). Optimal Control Theory with Economic Applications, Amsterdam: North-Holland.

[23] Shapiro, C. (1989). "Theories of Oligopoly Behaviour," in R. Schmalensee and R. Willig (eds.), Handbook of Industrial Organization, pp. 329-410, Amsterdam: North-Holland.

[24] Stenbacka, R. and M.M. Tombak (1997). "Commitment and Efficiency in Research Joint Ventures," in J. Poyago-Theotoki (ed.), Competition, Cooperation, Research and Development: The Economics of Research Joint Ventures, pp. 138158, Macmillan Publ. Co.

[25] Sutton, J. (2007). "Market Share Dynamics and the 'Persistence of Leadership' Debate," American Economic Review, 97 (1), 222-241.

[26] Tirole, J. (1991). The Theory of Industrial Organization, Cambridge, MA: The MIT Press. 
[27] Žigić, K. (1998). "Intellectual Property Rights Violations and Spillovers in NorthSouth Trade," European Economic Review 42, 1779-1799. 
Individual researchers, as well as the on-line and printed versions of the CERGE-EI Working Papers (including their dissemination) were supported from the European Structural Fund (within the Operational Programme Prague Adaptability), the budget of the City of Prague, the Czech Republic's state budget and the following institutional grants:

- Center of Advanced Political Economy Research [Centrum pro pokročilá politickoekonomická studia], No. LC542, (2005-2009),

- Economic Aspects of EU and EMU Entry [Ekonomické aspekty vstupu do Evropské unie a Evropské měnové unie], No. AVOZ70850503, (2005-2010);

- Economic Impact of European Integration on the Czech Republic [Ekonomické dopady evropské integrace na ČR], No. MSM0021620846, (2005-2011);

Specific research support and/or other grants the researchers/publications benefited from are acknowledged at the beginning of the Paper.

(c) Eugen Kováč, Viatcheslav Vinogradov, Krešimir Žigić, 2009

All rights reserved. No part of this publication may be reproduced, stored in a retrieval system or transmitted in any form or by any means, electronic, mechanical or photocopying, recording, or otherwise without the prior permission of the publisher.

Published by

Charles University in Prague, Center for Economic Research and Graduate Education (CERGE) and

Economics Institute ASCR, v. v. i. (EI)

CERGE-El, Politických vězňů 7, 11121 Prague 1, tel.: +420 224005 153, Czech Republic.

Printed by CERGE-EI, Prague

Subscription: CERGE-EI homepage: http://www.cerge-ei.cz

Editors: Directors of CERGE and EI

Managing editors: Deputy Directors for Research of CERGE and EI

ISSN 1211-3298

ISBN 978-80-7343-203-4 (Univerzita Karlova. Centrum pro ekonomický výzkum

a doktorské studium)

ISBN 978-80-7344-192-0 (Národohospodářský ústav AV ČR, v. v. i.) 
CERGE-EI

P.O.BOX 882

Politických vězňů 7

11121 Praha 1

Czech Republic http://www.cerge-ei.cz 